\title{
O ENSINO DO DIREITO ANIMAL: UM PANORAMA GLOBAL
}

\author{
Teaching animal law: a Global overview
}

\section{Tagore Trajano de Almeida Silva}

Pós-Doutorando pela Pace Law School (New York/USA). Doutor e Mestre em Direito Público da Universidade Federal da Bahia (UFBA). Visiting Scholar da Michigan State University (MSU/USA). Pesquisador Visitante da University of Science and Technology of China (USTC/China). Presidente do Instituto Abolicionista pelos Animais - IAA: www.abolicionismoanimal.org.br. Membro-fundador da Asociación Latinoamericana de Derecho Ambiental. Pesquisador do Núcleo Interdisciplinar de Pesquisa e Extensão em Direito Ambiental e Direito Animal - NIPEDA/ UFBA: www.nipeda.direito.ufba.br. Coordenador da Revista Brasileira de Direito Animal. E-mail: tagore@ufba.br.

RECEBIDO EM: 03.03.2013

APROVADO EM: 15.05.2013

\section{RESUMO}

Este artigo visa elaborar um panorama do ensino do Direito Animal no mundo ocidental. O debate moral iniciado na filosofia foi absorvido por diversos sistemas jurídicos através do seu corpo docente e discente, criando uma atmosfera adequada para repensar a teoria do direito e seus sujeitos. Através da visualização das diversas experiências pedagógicas existentes ao redor do planeta, buscou-se definir o atual estágio de desenvolvimento da matéria no Brasil. Sendo assim, a direção proposta é no sentido do reconhecimento do novo paradigma pós-humanista a influenciar uma reinterpretação dos conceitos jurídicos através do ensino do curso Direito Animal nas Faculdades de Direito.

Palavras-chave: Direito animal. Ensino jurídico. Pós-humanismo. Faculdade de DIREITO. DireITOS FUNDAMENTAIS

\section{Abstract}

This article aims to provide a World Animal Law courses overview in the Western world. The debate starts in moral philosophy and after it absorbed by various legal systems through its faculty and students, creating an atmosphere appropriate 
to rethink the theory of law and its subjects. Through visualization of the various existing educational experiences around the planet, we sought to define the current stage of development of the field in Brazil. Thus, the proposed direction is towards the recognition of the new paradigm posthumanist to influence a reinterpretation of legal concepts through teaching Animal Law course in the Law Schools.

Keywords: Animal law. Education law. Posthumanism. LaW school. Fundamental RIGHTS.

Sumário: Introdução: a busca de novas direções. 1. Do grupo de Oxford ao Oxford Centre for Animal Ethics. 2. A experiência dos Estados Unidos. 2.1. O papel dos professores. 2.2. O papel da academia e o aumento das publicações. 3. A experiência europeia: o ensino do direito animal em Portugal, Espanha e França. 4. A experiência brasileira. 4.1. Ensino do direito animal e seus professores. 4.2. Os grupos de pesquisa e extensão em direito animal. Conclusão. Referências.

\section{INTRODUÇÃO: A BUSCA DE NOVAS DIREÇÕES}

Durante muito tempo, o ensino do direito foi pensado através de uma metodologia orientada a se afastar dos valores sociais, construindo uma dogmática jurídica que se autodenominava pura, perfeita, já que tinha as mesmas características objetivas das ciências naturais ${ }^{259}$. Como forma de responder a esta forma de ensino, foi pensada uma nova dogmática, pós-humanizada, a fim de englobar os novos valores sociais, advindos da biologia, filosofia, genética, robótica e da cibernética ${ }^{260}$.

Neste contexto, seminários, cursos, grupos de pesquisa e palestras têm sido oferecidos nas instituições universitárias, a fim de evidenciar este novo momento pela qual passa o ensino jurídico. O grande número de Faculdades de Direito, a má-formação de alunos e professores, a falta de objetivos e rumos pedagógicos são fatores negativos citados para o agravamento da crise na educação neste campo do conhecimento ${ }^{261}$.

${ }^{259}$ Cf. KELSEN, Hans, Teoria pura do direito. Trad. João Baptista Machado. 6. ed. São Paulo: Martins Fontes, 1998.

${ }^{260}$ No campo do direito robótico, ver: CASTRO JÚNIOR, Marco Aurélio de. Direito e Pós -Humanidade: Quando os Robôs serão Sujeitos de Direito, Juruá, 2013.

${ }^{261}$ Sobre uma crítica da educação jurídica, ver: FARIA, José Eduardo. A Noção de Paradigma na Ciência do Direito: notas para uma crítica ao idealismo jurídico. In: FARIA, José Eduardo. (org). A Crise do Direito numa Sociedade em Mudança. Brasília: Editora UnB, 1988. pp. 14-30. 
Na verdade, o colapso não é apenas do ensino jurídico e da forma de abordagem de seu conteúdo, mas também da própria concepção do direito. A ordem jurídica busca oxigenar seu ordenamento, a fim de responder aos anseios de uma nova sociedade mais dinâmica e plural ${ }^{262}$.

Historicamente, a ciência jurídica pautou-se por um debate científico formalista que afirmava a autonomia absoluta do direito em relação ao mundo social. O direito era pensado de forma instrumental a ser reflexo ou utensílio a serviço de uma minoria influente ${ }^{263}$.

A relação estabelecida entre humanos e não-humanos fundou-se no critério de dominação. Os animais não-humanos têm servido como instrumento do desejo humano ao longo dos anos, tendo seu valor reconhecido a depender da utilidade econômica a que estão vinculados: bovinos, aves, peixes e suínos são vistos como alimentos; equinos para o trabalho e locomoção; caprinos para vestuário; primatas e roedores para experimentação. Nesta inter-relação o interesse jurídico somente era protegido quando vinculado ao empenho humano, ou seja, não havia consideração moral, ética e jurídica do animal que era pensado como objeto de uso dos seus semelhantes ${ }^{264}$.

A ruptura com esta forma de pensar o animal viria de dentro do próprio sistema jurídico. Autores como Jeremy Bentham ${ }^{265}$ e Henry Salt ${ }^{266}$ motivaram os operadores do direito a pensar o sofrimento animal e a criar medidas para evitar estas situações.

Motivados pelo trabalho destes autores, grandes centros universitários começaram a trabalhar com a temática dos animais não-humanos, tentando estabelecer saídas para o melhor convívio entre espécies. Desde o início dos estudos, o trabalho no campo do Direito Animal foi caracterizado pelo forte cunho transdisciplinar, combinando cientistas das mais diversas áreas de conhecimento para o estudo dos animais. Temas como racionalidade, linguagem, origem das espécies, intersubjetividade e sensibilidade foram abordados por cientistas das mais diversas universidades do planeta. Havia uma necessidade de se estabelecer o verdadeiro locus do animal na sociedade e sua relação com os humanos ${ }^{267}$.

${ }^{262}$ Cf. MORIN, Edgar. Ciência com Consciência. 8. ed. Rio de Janeiro: Bertrand Brasil, 2005. p. 167.

${ }^{263}$ Cf. BOURDIEU, Pierre. O Poder Simbólico. 6. ed. Rio de Janeiro: Bertrand Brasil, 2003. pp. 209-212.

${ }^{264}$ WARREN, Marry A. Moral Status: Obligations to Persons and Other Living Things. Oxford: Oxford University Press, 1997. p. 7.

${ }^{265}$ Cf. BENTHAM, Jeremy. An Introduction to the Principles of Morals and Legislation. London: W. Pickering, Linconln's inn fields and E. Wilson, Royal Exchange, 1823.

${ }^{266}$ Cf. SALT, Henry S. Animals' rights. In Animal rights and human obligations. New Jersey: Prencitce-hall, 1976.

${ }^{267}$ Exemplo de grupo transdisciplinar é o Projeto Grandes Primatas (The Great Ape Project) 
Realmente o estudo sobre os animais começou através da perspectiva de exploração, observação, levantamento e experimentação de recursos naturais, coletando estes seres junto à natureza como amostras de espécies e ecossistemas para posterior observação humana. Os principais financiadores destas explorações eram as Sociedades Científicas e os Museus de História Natural localizados na Europa nos Estados Unidos. O objetivo era classificar os objetos da natureza de acordo com as características morfológicas compartilhadas ${ }^{268}$.

Este fundamento filosófico interferiu na valoração moral e jurídica dos animais por séculos, uma vez que como objetos de observação, seres vivos, dentre eles animais humanos e não-humanos, foram sendo considerados objetos da ciência. Fazendo parte dos processos de pesquisa, durante muito tempo utilizaram-se estes seres em experimentações que tinham como objetivo o progresso científico ${ }^{269}$.

A concepção de ciência sem limites éticos e morais adentrou no direito de forma a fundamentar uma exploração legitimada e institucionalizada dos animais e do próprio homem, uma vez que o direito via com indiferença o emprego de práticas hoje concebidas como desumanas nos centros de pesquisa ${ }^{270}$.

Áreas como a Bioética e o Direito Animal surgem como forma de responder a estes constantes anseios sociais na direção da pós-humanização da sociedade, ao compreender os limites de cada ciência. O direito e seus profissionais são chamados a responder as mais variadas questões, devendo através da perspectiva dessas novas matérias, propor mudanças do paradigma vigente, a fim de possibilitar uma ruptura com este modelo e construção de um novo mais inclusivo ${ }^{271}$.

As próprias instituições de pesquisa buscaram iniciar a mudança, estimulando novas práticas de cooperação e alternativas para a não utilização de animais, humanos e não-humanos, em pesquisas científicas, por exemplo. Nesse instante, os interesses dos não-humanos foram colocados em pauta, porquanto para se ir adiante restou-se imprescindível uma transformação ${ }^{272}$.

criado em 1993 por Paola Cavalieri e Peter Singer. O projeto era formado por um grupo de cientistas que começaram a defender abertamente a extensão dos direitos humanos para os grandes primatas, dentre os nomes que se associaram ao projeto estavam: primatólogos como Jane Goodall, etólogos como Richard Dawkins e intelectuais como Edgar Morin. Sobre o projeto ver: CAVALIERI, Paola \& SINGER, Peter. (eds.). The Great Ape Project. New York: St. Martin's Griffin, 1993.

${ }^{268}$ BURKE, Peter. Uma história social do conhecimento II: Da enciclopédia à wikipédia. Rio de Janeiro: Editora Jorge Zahar, 2012. pp. 24-25.

${ }^{269}$ KEAN, Hilda. Animal rights: political and social change in Britain since 1800, Reaktion Books, 1998. pp. 33-96.

${ }^{270}$ PAIXÃO, Rita Leal \& SCHRAMM, Fermin Roland. Experimentação Animal. Razões e emoções para uma ética. EdUFF, Niterói, RJ, 2008. pp. 72-73.

${ }^{271}$ Ver, de forma geral: KUHN, Thomas S. A Estrutura das Revoluções Cientificas. Trad. Beatriz Vianna Boeira e Nelson Boeira. 9ª ed. São Paulo: Perspectiva, 2003. p. 116.

272 SENATORI, Megan A. \& FRASCH, Pamela D. The Future of Animal Law: Moving 
Dentro deste cenário, instituições de todo o mundo se mobilizaram para desenvolver alternativas para a defesa dos animais, dentre elas instituições brasileiras como a Universidade Federal da Bahia, pólo gerador de conhecimento jurídico sobre o tema ${ }^{273}$.

Este clima acadêmico favorável criado em torno da consideração jurídica e moral dos animais é sinal de crise do paradigma atual que gera uma inicial insegurança ${ }^{274}$, porém possibilita um sólido avançar científico na direção do fundamento pós-humanista. ${ }^{275}$

Sendo assim, no desenvolvimento do artigo, procurou-se retratar o panorama do ensino do Direito Animal no mundo ocidental, escrevendo a história a partir do ponto de vista de pesquisadores, docentes e discentes, abordando: 1) os efeitos da produção literária surgida na Universidade de Oxford; 2) a contribuição fornecida pelos pesquisadores estadunidenses à ciência do direito; 3) crescimento do debate europeu em torno da consideração jurídica dos animais; e, por fim, 4) a experiência brasileira na direção do reconhecimento do novo paradigma pós-humanista a influenciar uma reinterpretação dos conceitos jurídicos através do ensino do curso Direito Animal nas Faculdades de Direito.

\section{Do grupo de Oxford ao Oxford Centre for Animal Ethics}

Pode-se dizer que a Universidade de Oxford foi o berço para o surgimento do movimento de libertação animal, pois foi nos seus corredores que professores e estudantes começaram a criar uma teoria a considerar os interesses dos animais não-humanos.

Ainda em 1640, Robert Boyle, químico e fisiologista da instituição, afirmou que os animais eram dotados de razão, pois humanos e não-humanos eram produtos da divindade. Para Boyle, a crueldade imposta aos animais poderia gerar efeitos negativos na personalidade dos seres humanos. Estes não tinham o direito de causar sofrimento desnecessário aos animais, sendo considerado censurável matar apenas por prazer. Nesse sentido, práticas como brigas de galo, caça de ursos e lebres, maus-tratos a animais domésticos, encarceramento de animais selvagens, métodos brutais de abate e vivissecção, eram considerados barbaridades cometidas

Beyond Preaching to the Choir. Journal of Legal Education. Vol. 60. n.02. p. 209-236. November, 2010. pp. 235-236.

${ }^{273}$ A Universidade Federal da Bahia, através da Faculdade de Direito, iniciou um processo de mudança de paradigma na seara jurídica, englobando nas suas linhas de pesquisa o tema da Bioética e o Direito Animal. Sobre o assunto, ver: www.ppgd.ufba.br.

${ }^{274}$ CHALMERS, Alan F. O que é ciência afinal? 2. ed. São Paulo: Ed. Brasiliense, 1993. p. 131

${ }^{275}$ Ver conceito de progresso científico em: POPPER, Karl. Lógica das ciências sociais. 2. ed. Rio de Janeiro: Tempo Universitário, 2004. 
contra os não-humanos ${ }^{276}$.

O discurso de Boyle opunha-se à teoria dos animais autômatos de René Descartes $^{277}$, ao afirmar que Deus não poderia permitir que as criaturas sem pecado sofressem ${ }^{278}$. Ao retirar qualquer significado moral dos animais, Descartes equiparou os não-humanos a objetos destituídos de sentimento e razão ${ }^{279}$. Diferentemente, Boyle evidenciou similaridades entre a estrutura de corpos humanos e dos não-humanos, asseverando uma racionalidade para animais ${ }^{280}$. Embora ele afirme que esta razão seria inferior à humana, Boyle considerava o sofrimento gratuito dirigido aos animais um pecado ${ }^{281}$.

A mudança na relação entre homens e animais foi sentida pelos intelectuais britânicos que, em 1772, através de James Granger, vigário de Shiplake, Oxford, pregou o primeiro sermão registrado contra a crueldade animal ${ }^{282}$. No mesmo sentido, John Henry Newman, clérigo da Igreja da Universidade de St. Mary, na homilia da Sexta-feira Santa de 1842, sustentou que o sofrimento dos animais era moralmente equivalente ao sofrimento de Cristo na cruz ${ }^{283}$.

${ }^{276}$ THOMAS, Keith. O homem e o mundo natural: mudanças de atitude em relação às plantas e aos animais $(1500-1800)$. Trad. João Roberto Martins Filho. São Paulo: Companhia das Letras, 2010. p. 202.

277 Sobre a teoria de René Descartes, ver: HARRISON, Peter. Descartes on Animals. Philosophical Quarterly. Vol. 42. pp. 239-48. 1992.

${ }^{278}$ René Descartes contribuiu para excluir os animais da esfera das preocupações morais humanas. Ele justificava a exploração dos animais ao afirmar que eles seriam somente autômatos ou máquinas destituídas de sentimentos, incapazes, portanto, de experimentar sensações de dor e de prazer - teoria do animal-máquina. DESCARTES, René. Discurso do Método e Regras para a direção do Espírito. Trad. Pietro Nassetti. São Paulo: Martin Claret, 2007. pp. 56-58.

${ }^{279}$ LEVAI, Laerte Fernando \& DARÓ. Vânia Rall, Experimentação animal: histórico, implicações éticas e caracterização como crime ambiental. Revista de Direito Ambiental. São Paulo, Revista dos Tribunais, n. 36, out./dez., 2004. pp. 138-139.

${ }^{280}$ Sobre o tema ver: BYNUM, William F. The Anatomical Method, Natural Theology, and the Functions of the Brain. Isis. Vol. 64. No 04. p. 444-468. Dec., 1973. pp. 445-447.

${ }^{281}$ OSTER, Malcolm R. The 'Beame of Diuinity': Animal Suffering in the Early Thought of Robert Boyle. The British Journal for the History of Science. Vol. 22. No. 2. pp. 151-179. Jul, 1989. pp. 151-152.

${ }^{282}$ Homilia publicada em: GRANGER, James. An Apology for the Brute Creation, Or Abuse of Animals Censured. In: Sermon on Proverbs XII. 10. Preached in the Parish Church of Shiplake, in Oxfordshire, October 18, 1772.

${ }^{283}$ Diz John Newman em seu sermão: “(...) o nosso Senhor é chamado de cordeiro na Bíblia, isto é, Ele era tão indefeso e inocente como um cordeiro é. Desde então, a Escritura compara a este animal inofensivo e desprotegido, que pode, sem presunção ou irreverência tomar a imagem como um meio de transmitir às nossas mentes os sentimentos que os sofrimentos de nosso Senhor deve excitar em nós. Quero dizer, considere quão horrível é ler as notícias que, por vezes, encontrar-nos de crueldades exercidas em animais irracionais. Será que às vezes 
Lewis Carroll (Charles L. Dodgson) professor de matemática em Christ Church em 1875 publicou "Some Popular Fallacies about Vivisection" (Algumas falácias populares sobre a vivissecção), censurando as experimentações feitas com animais em Oxford ${ }^{284}$. A movimentação gerada pelo texto de Carroll culminou com a renúncia de John Ruskin da cadeira de "Slade Professor" em Belas Artes na Universidade de Oxford, por não concordar com a conduta adotada pelo centro universitário inglês ${ }^{285}$.

As discussões e debates acalorados criaram um ambiente favorável para a consideração dos interesses dos animais. Pesquisadores voltaram-se ao estudo da temática dos não-humanos, iniciando a construção do que viria a ser o embrião do movimento de libertação animal ${ }^{286}$.

Autores como Edward Nicholson ${ }^{287}$, C. J. Cadoux, C. S. Lewis ${ }^{288}$ e Austin Farrer, membros de Oxford, publicaram textos contrários à vivissecção e ao tratamento cruel dirigido aos animais não-humanos. Criava-se, na época, uma filosofia que reverenciava a vida e daria a Albert Schweitzer o Prêmio Nobel da Paz em $1952^{289}$.

Este clima vivido em Oxford corroborou com uma reviravolta científica propagada pela instituição britânica a colocar os animais não-humanos em lugar de

não nos fazem estremecer ao ouvir falar deles. Ao mesmo tempo, é a ação desenfreada dos proprietários que com raiva e de forma bárbara maltratam seus animais, e em outro, é o ato de sangue frio e calculista dos homens da ciência, que fazem experiências com animais irracionais, talvez apenas de uma espécie de curiosidade. (...) Pois o que era isso, mas a própria crueldade infligida a nosso Senhor?" (tradução do autor). NEWMAN, John Henry. Sermon Notes, 1849-1878. Longmans, Green \& Co, 1913. p. 113.

${ }^{284}$ Cf. CARROLL, Lewis. Some Popular Fallacies about Vivisection. Fortnightly Review. Vol. 17.102. May 1865-June 1934. Jun, 1875. pp. 847-854.

${ }^{285}$ John Ruskin considerava o aumento das pesquisas em animais vivos em laboratório de fisiologia um dos efeitos mais lamentáveis da interpretação das teorias de Darwin no campo da anatomia comparada. Ruskin entregou sua carta de demissão ao vice-reitor da Universidade após a aprovação de práticas de vivissecção no campus, alegando que “(...) pela tortura de milhares de animais, a saúde, a paz e a felicidade foram perdidas, porque os fisiologistas estavam continuamente infectando seus alunos não com a raiva comum do cão, mas com a raiva do homem (...)". MAYER, Jed. Ruskin, vivisection, and scientific knowledge. Nineteenth-Century Prose. Vol.35, Issue 1. pp. 200-266. Spring, 2008. p. 201.

${ }^{286}$ RYDER, Richard. Animal Revolution: Changing Attitudes Towards Speciesism. Basil Blackwell, 1989. pp. 113-116.

${ }^{287}$ Ver sobre o tema: NICHOLSON, Edward Williams Byron. The rights of an animal: a new essay in ethics. C. Kegan Paul \& Co, 1879.

${ }^{288}$ Ver sobre o trabalho do autor: LINZEY, Andrew. CS Lewis's theology of animals. Anglican Theological Review. Vol. 80. pp. 60-81. Winter, 1998. pp. 60-63.

289 Sobre este momento, ver o texto de: WARREN, Marry A. Moral Status: Obligations to Persons and Other Living Things. Oxford: Oxford University Press, 1997. p. 24. 
destaque, seja nos centros de pesquisa, como também nos debates sociais. Os animais deveriam ser pensados não mais como cobaias para experimentação humana, mas como detentores de valores éticos e morais a serem considerados pelo homem ${ }^{290}$.

Em 10 de outubro de 1965, o Sunday Times publicou uma coluna assinada por Brigid Brophy intitulada The rights of animals (Os direitos dos animais) ${ }^{291}$. Neste momento, percebeu-se que os debates tinham avançado para além dos muros de Oxford e ganhado as ruas. Era momento de progredir para a formação de uma base moral sólida na defesa da libertação animal ${ }^{292}$.

O panázio a engatilhar este movimento foi à publicação da coletânea "Animais, o homem e a moral" (Animals, Man and Morals) 293 , em 1971, publicada por três estudantes universitários de Oxford. Stanley e Rosalind Godlovitch e John Harris, junto com alguns professores como Richard Ryder, formaram o que viria a se chamar "Grupo de Oxford de Pesquisa sobre os Animais"

A geração do Grupo de Oxford vivenciava uma época em que os movimentos pelos direitos civis estavam em plena evolução, e a busca pelo fim do preconceito parecia ter esquecido os animais não-humanos ${ }^{295}$. Foi neste instante que, estabelecendo uma relação entre o racismo, o sexismo e o classismo, Richard Ryder cunhou a expressão "especismo" (speciesism) ${ }^{296}$.

${ }^{290}$ Sobre a relação da Universidade de Oxford com uma ética relacionada aos animais não -humanos, visitar: http://www.oxfordanimalethics.com/home/. Acessado em: 10.07.2013.

${ }^{291}$ Brigid Brophy, em seu texto, articulou que "a relação dos Homo sapiens com os outros animais é de constante exploração. Nós utilizamos o trabalho deles; alimentamo-nos e lhes transformamos em nosso vestuário. Nós os exploramos para que sirvam para nossas superstições, já que usamo-los em devoção aos nossos deuses, arrancando seus órgãos para previsão de nosso futuro, nós agora os sacrificamos em nome da ciência e experimentamos seus corpos na esperança - ou na mera tentativa - de que possamos ver um pouco melhor o presente". BROPHY, Brigid. The rights of animals. Sunday Times. Published in 10 October 1965.

${ }^{292}$ RYDER, Richard. Animal Revolution: Changing Attitudes Towards Speciesism. Basil Blackwell, 1989. p. 07.

${ }^{293}$ Cf. GODLOVITCH, Stanley, GODLOVITCH, Rosalind and HARRIS, John (eds.), Animals, Man and Morals: An Enquiry Into the Maltreatment of Non-Humans, London: Taplinger Publish Co, 1971.

${ }^{294}$ RYDER, Richard D. The Oxford Group. In BEKOFF, Marc, and CARRON Meaney. Encyclopedia of Animal Rights and Animal Welfare. Westport, CT: Greenwood Publishing Group, Inc., 1998. p. 261.

295 RYDER, Richard D. Os animais e os Direitos humanos. Revista Brasileira de Direito Animal. Vol. 04. pp. 67-70, 2008. p. 67.

${ }^{296}$ Richard Ryder estava em Oxford, em 1970, quando fez a relação da discriminação sofrida pelos animais não-humanos com a temática do racismo e do sexismo. Para divulgar suas ideias, Ryder escreveu um folheto e distribuiu pela Universidade de Oxford, contudo, na primeira tentativa não recebeu nenhuma resposta. Na segunda tentativa, conheceu Peter Singer que o convidaria para ser coautor em Libertação Animal. Porém, ele não aceitou. Em 
O grupo de Oxford receberia mais três adeptos: Andrew Linzey ${ }^{297}$, Stephen Clark $^{298}$ e Peter Singer ${ }^{299}$. Este último escreveu, em 1973, uma crítica intitulada $L i$ bertação Animal, sobre o livro "Animais, o homem e a moral" (Animals, Man and Morals), no New York Review of Book, dizendo que a publicação era um verdadeiro manifesto na defesa dos animais ${ }^{300}$. Singer expunha que a última fronteira remanescente de discriminação era a do especismo, devendo se avançar para um movimento

seguida, cópia do folheto: "Desde Darwin, os cientistas concordaram que não há uma 'misteriosa' diferença entre o ser humano e outros animais. Por que, então fazemos uma distinção moral quase total? Se todos os organismos estão em um contínuo físico, então devemos também estar no mesmo continuum moral. A palavra 'espécie', como a palavra 'raça', não é precisamente definível. Leões e tigres podem cruzar. Em condições especiais de laboratório, se, em breve, se puder acasalar um gorila com um professor de biologia - será a prole mantida em uma gaiola ou um berço? Costuma-se descrever o Homem de Neandertal como uma espécie separada de nós mesmos, uma espécie especial que sobreviveu na Era do Gelo. No entanto, a maioria dos arqueólogos acreditam agora que esta criatura não-humana praticada enterro ritual e possuía um cérebro maior do que nós. Suponha que o Abominável Homem das Neves indescritível, quando capturados, acaba por ser o último sobrevivente da espécie Neandertal, que nós dar-lhe um lugar na ONU ou iríamos implantar eletrodos em seu cérebro super-humano? Eu uso esses exemplos hipotéticos, mas possível, para chamar a atenção para a falta de lógica do nosso presente moral posição no que respeita às experiências com animais. Cerca de cinco milhões de animais de laboratório, cada vez mais deles primatas como nós, são mortos todos os ano só no Reino Unido, e os números estão agora escalada fora de controle. Para além do Direito de viver, um critério moral claro é o sofrimento, o sofrimento da prisão, medo e tédio, bem como a dor física. Se assumirmos que o sofrimento é uma função do sistema nervoso, então é ilógico argumentar que outros animais não sofrem de uma forma semelhante à que se estabeleceu-se precisamente por alguns outros animais têm sistema nervoso. Os únicos argumentos em favor de experiências dolorosas em animais são: 1) que o avanço da conhecimento justifica todos os males, bem, não é? 2) que os possíveis benefícios para a nossa própria espécie justificar maus tratos de outras espécies, este pode ser um argumento bastante forte quando se aplica a experiências em que as possibilidades de sofrimento são mínimos e a probabilidade de ajudar a medicina aplicada é grande, mas mesmo assim ainda é apenas 'Especismo', e, como tal, é um argumento emocional egoísta ao invés de um único fundamentado. Não tenha medo de expressar seus pontos de vista. Contem aos parlamentares, professores, editores de revistas sobre esta questão moral cada vez mais importante". RYDER, Richard D. Speciesism Again: The Original Leaflet. Critical Society. Spring, Issue 2, 2010. pp. 01-02.

${ }^{297}$ Cf. LINZEY, Andrew. Animal Rights: A Christian Assessment of man's. London: SCM Press, 1976.

${ }^{298}$ Cf. CLARKE, Stephen R. L. The Moral Status of Animals. Oxford: Oxford University Press, 1977.

${ }^{299}$ Cf. SINGER, Peter. Animal Liberation: a New Ethics for our Treatment of Animals. New York: New York Review/Random House, 1975.

${ }^{300}$ CHIASSONI, Pierluigi. L'inescusabile specismo del mangiatore di tartare divagazioni sui diritti degli animali. Revista Brasileira de Direito Animal. Vol. 07. Ano 05. jul./dez. pp. 1341. Salvador: Evolução, 2010, p. 26. 
de libertação a expandir os horizontes morais, de modo que práticas anteriormente consideradas naturais e inevitáveis fossem vistas como inaceitáveis ${ }^{301}$.

A revisão feita por Singer ganha uma repercussão muito grande nos Estados Unidos, sendo o estudante australiano convidado a pesquisar na Universidade de Nova Iorque e a lançar seu livro por aquela editora ${ }^{302}$. Comentando o caso, Tom Regan pontuou que foi a primeira vez que a revisão de um livro ficou mais famosa do que o livro revisado ${ }^{303}$. Em 1975, Peter Singer lançou "Libertação Animal" (Animal Liberation) e Richard Ryder, "Vítimas da ciência" (Victims of Science) ${ }^{304}$.

Não demoraria para acontecer a primeira grande Conferência internacional sobre direitos dos animais em 1977. Organizada por Ryder, juntamente com Andrew Linzey na Trinity College, em Cambridge, tendo como resultado a publicação de Animal Rights: Symposium em 1979 ${ }^{305}$, onde constava "A declaração contra o Especismo" $" 306$.

O grupo de Oxford foi protagonista de uma série de mudanças filosóficas, jurídicas e éticas em torno dos animais, sendo responsáveis por estabelecer uma interrelação entre o conhecimento acadêmico com as demandas sociais.

Em 2006, Andrew Linzey funda o Oxford Centre for animal Ethics com o objetivo de contribuir com o debate político esclarecido sobre os animais não-humanos, estabelecendo uma agenda acadêmica de publicação e formação de intelectuais na área. Linzey contou com o apoio de mais de cem acadêmicos ${ }^{307}$, dentre eles o prêmio Nobel J. M. Coetzee ${ }^{308}$. Atualmente, conta com a participação de um profes-

${ }^{301}$ Ver sobre a exposição completa em: SINGER, Peter. Animal liberation. The New York Review of Books. Vol. 20. No 05. Publicado em 05 de Abril de 1973.

302 RYDER, Richard D. The Oxford Group. In BEKOFF, Marc, and CARRON Meaney. Encyclopedia of Animal Rights and Animal Welfare. Westport, CT: Greenwood Publishing Group, Inc., 1998. p. 262.

303 REGAN, Tom. The More Things Change. A review of Richard Ryder's. Animal Revolution: Changing Attitudes. Towards Speciesism. Between the Species. p. 110-115. North Carolina State University, Spring 1991. p. 110.

${ }^{304}$ Cf. RYDER, Richard D. Victims of Science: The Use of Animals in Research. London: David-Poynter, 1975.

305 Cf. PATERSON, David \& RYDER, Richard D. Animals' Rights: A Symposium. Open Gate Press, 1979.

${ }^{306}$ REGAN, Tom. The More Things Change. A review of Richard Ryder's. Animal Revolution: Changing Attitudes. Towards Speciesism. Between the Species. p. 110-115. North Carolina State University, Spring 1991. p. 111.

${ }^{307}$ Ainda em Oxford, pode-se encontrar o VERO - Voice for ethical research at Oxford, contando com o apoio de Ryder e Coetzee. Sobre o grupo ver: http://www.vero.org.uk/default. asp. Acessado em: 10 de Julho de 2013.

${ }^{308}$ Sobre o apoio dado ao centro de pesquisa de Oxford ver: SIMPSON, Matthew. Coetzee in Oxford. Oxford Magazine. N. 289. Trinity Term 2009. 
sor brasileiro, Carlos Naconecy, ${ }^{309}$ que vem desenvolvendo estudos na área de Ética Animal.

O movimento filosófico atravessa o Oceano Atlântico e encontra nas universidades estadunidenses terreno fértil para desenvolver uma teoria jurídica em torno dos animais.

\section{A experiênCia dos Estados Unidos}

A transferência dos fundamentos filosóficos da Inglaterra para os Estados Unidos não aconteceu de forma espontânea, ao contrário, necessitou de um trabalho árduo de organizações, associações e diretores de faculdades que reivindicaram na sociedade a legitimação do debate pelos direitos para os animais ${ }^{310}$. Para um número considerável de pessoas, o curso de Direito Animal era visto como uma novidade esporádica que logo iria acabar ${ }^{311}$. Contudo, com o passar dos anos, já são visualizadas mais de cento e quarenta Faculdades de Direito nos Estados Unidos ministrando Direito Animal, seja como matéria obrigatória ou como matéria eletiva em seus currículos $^{312}$.

O primeiro curso de Direito Animal dos Estados Unidos foi em 1977, na Seton Hall Law School, em Newark/New Jersey, ministrado por Theodore Sager Meth sob o nome de "A lei e os animais" (The Law and Animals). O componente curricular surgiu depois que alunos pediram a inserção da matéria para os diretores da Faculdade como uma forma de entenderem a questão animal difundida por Peter Singer em seu livro Libertação Animal, porém a disciplina apenas durou um semestre devido à falta de apoio institucional ${ }^{313}$.

Logo vieram os cursos da Dickinson School of Law na Penn State University, em 1983, ministrado pelos Professores Les MacRae e Geoffrey R. Scott, denominado "A lei dos animais" (The Law of Animals) e em 1985, o curso da Pace Law School, lecionado por Jolene Marion, desta vez, em formato de seminário (Animal

${ }^{309}$ Ver trabalho publicado do autor em Oxford: NACONECY, Carlos. Review Ethics and Animals: An Introduction Gruen Lori Cambridge University Press Cambridge, England. Journal of Animal Ethics. Vol. 02. pp. 222-224, 2012.

${ }^{310}$ Cf. SENATORI, Megan A. \& FRASCH, Pamela D. The Future of Animal Law: Moving Beyond Preaching to the Choir. Journal of Legal Education. Vol. 60. n.02. pp. 209-236. November, 2010.

311 Ver este debate em: FAVRE, David. The Gathering Momentum. Journal of Animal Law Vol. 01. 2005. p. 03. Em português, FAVRE, David. O ganho de força dos Direitos dos animais. Revista Brasileira de Direito Animal. Vol. 01. Nº. 01, (jan/dez. 2006). Salvador: Instituto Abolicionista Animal, 2006.

312 Ver acompanhamento do número de Faculdades de Direito nos Estados Unidos e Canadá no site da ALDF, disponível em: http://aldf.org/animal-law-courses/. Acessado em: 01 de Agosto de 2013.

${ }^{313}$ TISCHLER, Joyce. Building our Future. Animal Law. Vol. 15. pp. 01-07. 2008. p. 02. 
Law Seminar $)^{314}$.

Entre os anos 1970 até 2000, poucas Faculdades de Direito nos Estados Unidos instituíram o curso de Direito Animal. Entretanto, o cenário mudou através do estímulo que ocorreu no país por meio da realização de conferências, publicação de revistas e periódicos acadêmicos, criação de fundos específicos de pesquisa e fomento, além da formação de programas de pós-graduação e pesquisa no campo do Direito Animal. Somam-se a estes fatores, o importante papel realizado pelas comissões de Direito Animal da ABA (Ordem dos Advogados dos Estados Unidos) - Bar Association Animal Law Sections and Committees e o trabalho desenvolvido pela ALDF - Fundo de Defesa dos Animais ${ }^{315}$.

Em pouco tempo, os Estados Unidos tornaram-se referência na área de Direito Animal, porquanto houve: 1) um grande crescimento no número de instituições que oferecem o curso de Direito Animal; 2) o reconhecimento da autonomia da disciplina por parte das Faculdades de Direito, culminando com a criação de cadeiras de tempo integral junto ao seu corpo docente; 3 ) um estímulo a maior produção acadêmica; e 4) a adoção da matéria em faculdades como Duke, Harvard e New York, mais conservadoras, o que ajudou a fomentar a criação de grupos de pesquisa para estudar a consideração jurídica dos animais ${ }^{316}$.

O desenvolvimento de uma infraestrutura a suportar esta mudança de paradigma proposta pelo Direito Animal foi sendo criada principalmente pelos centros de pesquisa jurídica norteamericana, sendo que, dentre eles, destacam-se o trabalho desenvolvido pelos Professores: Steven Wise ${ }^{317}$ (Harvard Law School), David Favre (Michigan State University College of Law), David Cassuto (Pace Law School), Pamela Frash e Kathy Hessler (Lewis \& Clark Law School); em suas instituições.

Os professores Wise, Favre, Cassuto, Frash e Hessler colaboraram para o incremento deste campo do saber jurídico, instituindo parcerias, publicações, sites de pesquisa e acordos entre instituições que permitiram o avanço do Direito Animal não apenas nos Estados Unidos como também fora de seu território.

\subsection{O PAPEL DOS PROFESSORES}

Quando, em 1999, o jornalista William Glaberson escreve no New York Times o artigo intitulado "Juristas de vanguarda tentam elevar o status dos animais"

\footnotetext{
314 TISCHLER, Joyce. A Brief History of Animal Law, Part I (1972-1987). Stanford Journal of Animal Law and Policy. Vol. 01. p. 01-49. 2008. p. 10.

315 TISCHLER, Joyce. Building our Future. Animal Law. Vol. 15. p. 01-07. 2008. p. 02.

316 SANKOFF. Peter, Charting the Growth of Animal Law in Education. Journal of Animal Law. Vol. 04. p. 105-148. 2008. p. 109.

317 Steven Wise foi professor substituto na Faculdade de Direito de Harvard. Um professor substituto (nos EUA) ensina apenas uma parte do tempo, nem sempre pago, e não pode assumir responsabilidades acadêmicas nos órgãos da Faculdade.
} 
(Legal Pioneers Seek to Raise Lowly Status of Animals), talvez ele soubesse da importância que faria para o progresso do Direito Animal como campo específico de conhecimento jurídico nas Faculdades de Direito dos Estados Unidos ${ }^{318}$.

Glaberson atestou o momento de legitimação social da matéria que causaria um aumento na formação de grupos de pesquisa e a diminuição dos obstáculos psicológicos e conceituais em torno da consideração moral e jurídica dos animais ${ }^{319}$. A partir de então, o sistema judicial passou a ser percebido como um espaço estratégico de mudança de paradigma em torno dos animais, crescendo o entendimento no qual o Poder Judiciário colaboraria para a transformação do status jurídico do animal não-humano ${ }^{320}$.

A exposição da matéria colaborou com mudanças de atitude em relação aos animais, aumentando a legitimação popular. Professores como David Favre, Steven Wise, Taimie Bryant e Thomas Kelch fizeram parte do início do processo de conscientização pela disciplina Direito Animal ${ }^{321}$, em que o intuito era estimular uma metodologia voltada à diversidade de opiniões, compromisso com o pensamento crítico e a discussão aberta e criativa ${ }^{322}$.

De forma pioneira, a disciplina "Direito Animal" foi introduzida nos currículos das instituições onde lecionavam, formando os primeiros centros de pesquisa sob o tema nos Estados Unidos. A Michigan State University College of Law, por exemplo, em 1983, começou a oferecer o curso de Wildlife Law, ministrado por David $\mathrm{Favre}^{323}$, tendo como objetivo da matéria pautar as questões relativas à natureza

${ }^{318}$ O New York Times franquia acesso gratuito ao texto em: GLABERSON, William. Legal Pioneers Seek to Raise Lowly Status of Animals. The New York Times. Publicado em: 18 de Agosto de 1999. Disponível em: http://query.nytimes.com/gst/fullpage.html?res=9500E2DE1638F93BA2575BC0A96F958260\&sec=\&spon=\&pagewanted=2. Acessado em: $01 \mathrm{de}$ Agosto de 2013.

319 BARTLETT, Steven J. Roots of Human Resistance to Animal Rights: Psychological and Conceptual Blocks. Animal Law, v. 8, pp. 143-176 (2002). p. 149. Ver, em português, BARTLETT, Steven J. Raízes da resistência humana aos direitos dos animais: Bloqueios psicológicos e conceituais. Revista Brasileira de Direito Animal. Salvador: Evolução, Vol.2, n.3, pp. 17-66, jul./dez. 2007.

320 Sobre o tema, ver: WISE, Steven M. The Entitlement of Chimpanzees to the Common Law Writs of Habeas Corpus and de Homine Replegiando. Golden Gate Law Review. Vol. 37.2. Winter, 2007. p. 220.

${ }^{321}$ TISCHLER, Joyce. A Brief History of Animal Law, Part II (1985 -2011). Stanford Journal of Animal Law and Policy. Vol. 5. pp. 27-77. 2012. p. 36.

322 WALDAU, Paul. Law \& Other Animals. In Teaching the Animal: Human-animal studies across the disciplines New York: Margo DeMello ed, 2010. p. 218.

${ }^{323}$ Favre ainda, em 1979, defendia que "cada vez mais era evidente que o sistema jurídico norte-americano começaria a reconhecer e implementar uma nova área de Direito expressamente preocupada com a questão dos animais. Embora o termo 'Wildlife Law' possa parecer estranho, conceitualmente, as recentes leis federais e suas interpretações judiciais têm se 
jurídica, instrumentos processuais e tratados internacionais referentes aos animais não-humanos ${ }^{324}$.

$\mathrm{O}$ oferecimento de uma disciplina que considerasse os interesses dos animais gerou um efeito cascata para a proposta de mudanças jurídicas possíveis no ordenamento jurídico estadunidense, principalmente depois que ela começou a ser lecionada na Harvard Law School por Steven Wise ${ }^{325}$. Steven Wise militava como advogado em Boston e foi responsável por algumas decisões favoráveis aos animais naquela região. Junto com Favre, atuou no Fundo de Defesa Animal - (Animal Legal Defense Fund - $A L D F$ ), colaborando para que a Ordem dos Advogados norteamericana (American Bar Association - $A B A$ ) apoiasse a causa animal ${ }^{326}$.

Para Joyce Tischler, o apoio da ABA foi decisivo para a criação e suporte do Direito Animal perante advogados animalistas e tribunais ${ }^{327}$, pois eram as comissões criadas pelas seccionais que davam apoio jurídico e doutrinário aos operadores deste novo campo do direito ${ }^{328}$.

O envolvimento de instituições como: a ABA e a ALDF fez surgir uma demanda crescente para formação de profissionais na área de Direito Animal, sendo necessário a definição de materiais didáticos, planos de ensino, especializações e publicações para o aperfeiçoamento profissional dos jusanimalistas. O crescimento da matéria não se limitava apenas ao contexto norteamericano, avançando para países como o Brasil ${ }^{329}$.

David Cassuto, professor da Pace Law School, é um dos responsáveis pelo intercâmbio cultural com o Brasil através do Instituto Brasil-EUA de Direito e Meio Ambiente (Brazil-American Institute for Law and Environment - BAILE). Cassuto leciona na única instituição americana que possui um doutorado ( $S J D$-Doctor of Juridical Science) voltado para as questões ambientais e animais, o que colabora para

incomodado com a relação humano x não-humanos, a fim de controlar alguns dos conflitos mais graves entre os demais animais e os seres humanos". FAVRE, David. Wildlife Rights: The Ever Widening Circle. Environmental Law. Vol. 09. pp. 241-281. 1979.

${ }^{324}$ Em 2002, David Favre criou o Animal Legal \& Historical Center, contendo o maior banco de dados mundial em torno da questão dos animais. Este espaço tornou-se fundamental para desenvolvimento do tema e o fácil acesso às informações sobre os não-humanos. Sobre o website, favor acessar: www.animallaw.info. Acessado em: 01 de agosto de 2013.

${ }^{325}$ WISE, Steven M. The Evolution of Animal Law since 1950. In The State of the Animals II: 2003. p. 104.

${ }^{326}$ ORTIZ, Fran. Animal Law in the Classroom. Texas Bar Journal. Vol. 74. № 10. pp. $902-$ 904. November 2011. p. 903.

327 TISCHLER, Joyce. A Brief History of Animal Law, Part II (1985 -2011). Stanford Journal of Animal Law and Policy. Vol. 5. pp. 27-77. 2012. p. 35.

328 ORTIZ, Fran. Animal Law in the Classroom. Texas Bar Journal. Vol. 74. № 10. pp. $902-$ 904. November 2011. p. 903.

329 TISCHLER, Joyce. A Brief History of Animal Law, Part II (1985 -2011). Stanford Journal of Animal Law and Policy. Vol. 5. pp. 27-77. 2012. p. 35. 
a interrelação com Universidades como a Federal da Bahia e a Faculdade Getúlio Vargas (FGV/RIO), onde ele tem ministrado aulas e participado do progresso das discussões deste país ${ }^{330}$.

\subsection{O PAPEL DA ACADEMIA E O AUMENTO DAS PUBLICAÇÕES}

Em 1993, estudantes e alguns egressos da Lewis \& Clark Law School como Nancy Perry fundaram o primeiro periódico dedicado exclusivamente à publicação de artigos de Direito Animal. A Revista Animal Law consagrou-se rapidamente entre os periódicos nos Estados Unidos, uma vez que abriu espaço para discussão de novas interpretações dos institutos jurídicos a fim de preservar o interesse dos animais não-humanos ${ }^{331}$.

Em pouco tempo, outras revistas foram publicadas em instituições de ensino superior ao redor do país, estimulando seus centros de pesquisa e seus estudantes no desenvolvimento da matéria. Os periódicos Stanford Journal of Animal Law and Policy, Journal of Animal Law (Michigan State), Journal of Animal Law and Ethics (University of Pennsylvania) e o Journal of Animal \& Environmental Law (University of Louisville) corroboraram com o crescimento do debate jurídico-filosófico e com a criação da disciplina Direito Animal ${ }^{332}$.

Foi a partir das publicações da revista Animal Law que se percebeu a necessidade da criação de uma linha de pesquisa em Direito Animal na Faculdade de Direito Lewis \& Clark, contribuindo para a formação de intelectuais voltados para o debate em favor dos animais. A Lewis \& Clark Law School rapidamente se destacou no campo do Direito Animal. Em 2001, houve a fundação do Centro Nacional de Pesquisa em Direito Animal (Center for Animal Law Studies) e de um programa de pós-graduação exclusivamente voltado para as preocupações com os animais não -humanos, fornecendo material teórico e prático para a formação de novos profissionais do direito ${ }^{333}$.

De fato, professores e estudantes da Lewis \& Clark construíram um feixe

\footnotetext{
${ }^{330}$ O objetivo do Instituto Brasil-EUA de Direito e Meio Ambiente - Baile é trabalhar na melhoria da proteção ambiental e animal, promovendo a reflexão da legislação em busca de interpretações mais eficazes para os envolvidos. O Instituto estimula a cooperação internacional para estimular e aperfeiçoar a legislação ambiental progressiva em ambos os países. Mais informações em: http://www.law.pace.edu/BAILE. Acessado em: 01.08.2013.

${ }^{331}$ PERRY. Nancy V. Ten Years of Animal Law at Lewis \& Clark Law School. Animal Law. Vol. 09. p. ix-Xv. 2003. p. ix.

332 Sobre os periódicos que tratam da proteção animal no sistema jurídico norte-americano, visitar: http://aldf.org/resources/law-professional-law-student-resources/law-students-saldfchapters/animal-law-books-periodicals/. Acessado em: 01.08.2013.

${ }^{333}$ Sobre a evolução da Lewis \& Clark Law School no contexto norte-americano, acessar o site da instituição em: http://law.lclark.edu/centers/animal_law_studies/about_us/. Acessado em: 01.09.2013.
} 
de materiais didáticos exclusivo no campo do Direito Animal, possibilitando que outras instituições tivessem acesso a um conteúdo didático-pedagógico em torno da matéria ${ }^{334}$. O currículo do curso de Direito Animal foi pensado a oferecer aos alunos as mais diversas perspectivas do tratamento animal, de forma a não priorizar correntes filosóficas ou abordagens pessoais, avançando as discussões do campo teórico e filosófico para debates práticos e jurídicos em torno dos problemas que poderiam ser encontrados durante o aprendizado profissional dos alunos ${ }^{335}$.

A Lewis \& Clark conseguiu ao decorrer dos anos edificar uma pós-graduação sólida no campo do Direito Animal, tendo o primeiro mestrado na área em parceria com a ABA - American Bar Association e do Fundo de Defesa dos Animais (Animal Legal Defense Fund-ALDF) ${ }^{336}$.

De acordo com David Cassuto, esta evolução do estudo do Direito Animal pode estabelecer um currículo mínimo para a compreensão da matéria, abordando temas como: a) o movimento pelos direitos dos animais; b) o desenvolvimento das leis anticrueldade; c) avanço das legislações estaduais e federais; d) experimentação e vivissecção animal; e) animais usados como entretenimento, para fins religiosos ou para fins educativos; f) abate humanitário, dentre outros. Para Cassuto, estes assuntos devem sempre ser tratados de forma a estabelecer uma conexão entre as questões ambientais e as questões dos animais, propondo uma nova interpretação desses sujeitos de direito ${ }^{337}$.

Desta forma, um currículo plural possibilita ao estudante desenvolver um raciocínio, levando em consideração os interesses dos animais não-humanos através de uma abordagem diferenciada para cada nível de instrução. Na graduação, o curso oferecido contém um panorama geral dos temas de Direito Animal ${ }^{338}$, sendo a disciplina oferecida nos primeiros anos do curso de direito ${ }^{339}$. Já na pós-graduação, há a possibilidade de aprofundamento de cada um dos tópicos do panorama visto na

${ }^{334}$ Pamela Frash, professora da instituição, foi a primeira diretora e coautora de um casebook sobre Direito Animal. Cf. WAISMAN, Sonia S.; FRASCH, Pamela D. \& WAGMAN, Bruce. A. Animal Law: Cases and Materials. 3. ed. Durham, NC: Carolina Academic Press 2006.

335 SENATORI, Megan A. \& FRASCH, Pamela D. The Future of Animal Law: Moving Beyond Preaching to the Choir. Journal of Legal Education. Vol. 60. n.02. pp. 209-236. November, 2010. p. 210.

${ }^{336}$ Sobre o Animal Law LL.M, ver: https://law.lclark.edu/centers/animal_law_studies/curriculum/LLM/. Acessado em: 01.08.2013.

${ }^{337}$ Ver o plano de aula do Professor David Cassuto no site: http://www.law.pace.edu/faculty/ david-n-cassuto. Acessado em: 01.08.2013.

338 A Lewis \& Clark Law School, por exemplo, chama a disciplina de Direito Animal - um panorama - (Animal Law - an overview). Sobre a disciplina oferecida no juris doctor da instituição ver: http://law.lclark.edu/centers/animal_law_studies/about_us/.Acessado em: 01 .08.2013.

339 DECKHA, Maneesha. Teaching Posthumanist Ethics in Law School: The Race, Culture, and Gender Dimensions of Student Resistance. Animal Law. Vol. 16. pp. 287-315. p. 313. 
graduação, aprofundando temas no campo da filosofia, epistemologia, teoria geral e da dogmática animal ${ }^{340}$.

A visão do Direito Animal como disciplina autônoma já é uma realidade em países como os Estados Unidos, Canadá, Inglaterra, China, Austrália, Nova Zelândia, Portugal, Itália, Espanha, Índia e Brasil ${ }^{341}$. As experiências trazidas por meio de cada uma dessas nações têm enriquecido o debate e proporcionado uma verdadeira revolução nos conceitos estabelecidos pela Teoria Geral do Direito contemporâneo ${ }^{342}$.

\section{A experiência europeia: o ensino do direito animal em Portugal, Es- Panha e França}

Para progredir na discussão sobre a proteção dos interesses dos animais, a Europa continental foi buscar nos Estados Unidos os fundamentos para uma mudança de perspectiva dentro do direito. Este intercâmbio cultural a cruzar novamente o Atlântico possibilitou que se criassem, em terras europeias, grandes centros de conhecimento em torno da temática animal.

Alguns países da Europa, especialmente os ibéricos, são marcados por tradições de maus-tratos aos animais. Eventos como a farra do boi e as touradas são secularmente conhecidos pelo sofrimento causado aos não-humanos. Entretanto, o panorama tem mudado, uma vez que o suporte popular a estes espetáculos tem diminuído progressivamente ao passar dos anos ${ }^{343}$.

Em Portugal, as Faculdades de Direito têm percebido a seriedade da discussão para o sistema jurídico, incorporando em cursos de especialização ou na própria graduação o Direito Animal. Da mesma forma, há um crescente interesse público sobre as questões que envolvem os não-humanos, além de uma transformação legislativa em torno da temática com intuito de adequar Portugal às normas do

\footnotetext{
${ }^{340}$ Cf. ANDRZEJEWSKI, Julie. Teaching Animal Rights at the University: Philosophy and Practice. Journal for Critical Animal Studies. Vol. 01. pp. 01-12. 2003. pp. 2-5.

${ }^{341}$ Sobre a evolução do Direito Animal no mundo ver o texto de: SANKOFF. Peter, Charting the Growth of Animal Law in Education. Journal of Animal Law. Vol. 04. pp. 105-148. 2008. 342 Outro país que vem avançando no debate do Direito Animal é a Argentina, destacando-se o trabalho de Pablo Buompadre que, desde 2011, tem se empenhado no trabalho em torno do reconhecimento do Direito Animal como disciplina autônoma na Argentina.

343 BORJA-SANTOS, Romana. Sintra proíbe touradas e espectáculos de circo com animais. Portugal. Publicado em: 27/04/2009 às 16:58h. Disponível em: http://www.publico.pt/sociedade/noticia/sintra-proibe-touradas-e-espectaculos-de-circo-com-animais-1377028. Acessado em: 01.08.2013.
} 
Direito Europeu ${ }^{344}$. Com efeito, Antônio Maria Pereira, ${ }^{345}$ deputado português, em 1995, conseguiu aprovar em 12 de setembro a Lei $n^{\circ}$ 92, a legislação em favor dos animais no contexto português. Conhecida como Lei de Proteção Animal, a Lei de 1995 acendeu um debate sobre o tratamento dos animais não-humanos ${ }^{346}$.

Outro momento marcante em Portugal sobre o discurso em prol de direitos para os animais veio a acontecer em 2003 com a publicação do livro $A$ hora dos Direitos dos Animais, de Fernando Araújo ${ }^{347}$. Professor da Universidade de Lisboa, Araújo tem participado ativamente da guinada portuguesa em torno dos interesses dos não-humanos, sendo um dos responsáveis pelo avanço da proteção jurídica desses seres nos países de língua portuguesa. Este esforço vai além das fronteiras de Portugal, colaborando com a supervisão e orientação de professores brasileiros no campo do Direito Animal ${ }^{348}$.

O papel de Fernando Araújo lecionando e propagando os ideais do Direito Animal foi importante para a mudança do comportamento em relação aos não-humanos. Em estudo realizado pelo Centro de Investigação e Estudos de Sociologia - CIES - foi constatado que a esmagadora maioria dos pesquisados pensa que os animais são pouco ou nada protegidos em Portugal, sendo papel das instituições públicas mudar este cenário de abuso e maus-tratos com estes seres. ${ }^{349}$

A proposta de um Direito Animal Português, deste modo, é no sentido de se criar um estatuto jurídico dos animais não-humanos a compreender de forma interdisciplinar as normas de Direito Animal e sua relação com os outros ramos do Direito, tais como Penal, Civil, Administrativo, Ambiental e Constitucional ${ }^{350}$.

Um Código Animal Português seria um progresso da Legislação Ambien-

${ }^{344}$ ARAÚJO, Fernando. The Recent Development of Portuguese Law in the Field of Animal Rights. Journal of Animal Law. Vol. 01. pp. 61-72. 2005. pp. 61-63.

${ }^{345}$ MOUTINHO, Miguel. O Direito dos Animais e os Direitos dos Animais. In Os animais e a lei. Publicado em 11 de Abril de 2009. Disponível em: http://osanimaisealei.blogspot.com. br/2009/04/o-Direito-dos-animais-e-os-Direitos-dos.html. Acessado em: 03.08.2013.

${ }^{346}$ ARAÚJO, Fernando. The Recent Development of Portuguese Law in the Field of Animal Rights. Journal of Animal Law. Vol. 01. pp. 61-72. 2005. p. 62.

${ }^{347}$ Cf. ARAÚJO, Fernando. A Hora dos Direitos dos Animais. Coimbra: Almedina, 2003.

${ }^{348}$ Exemplo é a orientação feita ao Professor brasileiro Anderson Furlan, doutorando na Universidade de Lisboa e pesquisador no campo do Direito Animal. Sobre o autor, ver: FURLAN, Anderson \& FRACALOSSI, William. Direito ambiental. Rio de Janeiro: Forense, 2010.

${ }^{349}$ Cf. MONTEIRO, Teresa Líbano, POLICARPO, Verónica \& SILVA, Francisco Vieira da (Coords.) Valores e Atitudes face à Protecção dos Animais em Portugal - Inquérito Nacional. In Centro de Investigação e Estudos de Sociologia (CIES) do ISCTE - Instituto Superior de Ciências do Trabalho e da Empresa. Maio de 2007.

${ }^{350}$ MOUTINHO, Miguel. O Direito dos Animais e os Direitos dos Animais. In Os animais e a lei. Publicado em 11 de Abril de 2009. Disponível em: http://osanimaisealei.blogspot.com. br/2009/04/o-Direito-dos-animais-e-os-Direitos-dos.html. Acessado em: 03.08.2013. 
tal para além do conceito de espécies animais como objeto, ${ }^{351}$ concebendo uma mudança de paradigma no sistema jurídico português para reconhecer um novo status jurídico ao animal considerado de forma individual, afastando-se de conceituações que ponderam apenas o valor humano destes seres.

Nesta esteira, a academia portuguesa propõe uma revisão do Código Civil e da Constituição Portuguesa, a fim de englobar uma interpretação que reconheça o interesse fundamental na salvaguarda do bem-estar e na minimização do sofrimento do animal não-humano, inclusive na esfera privada ${ }^{352}$.

De igual modo, os espanhóis têm dado passos firmes para atenuar as constantes violações em torno dos interesses dos animais não-humanos. Como forma de se adequar às diretivas da União Europeia, o Parlamento espanhol aprovou, em 2007, a Lei $\mathrm{n}^{\circ} 32$, que estabelece normas benestaristas a equilibrar os interesses humanos e não-humanos na utilização dos animais ${ }^{353}$.

Outro avanço importante foi à aprovação pela comunidade autônoma da Catalunha, em 2010, da lei de iniciativa popular que proíbe a prática das touradas em seu território. A proibição foi resultado de uma manifestação popular que angariou cerca de 180.000 assinaturas com a finalidade de eliminar o uso de animais em espetáculos públicos que possam trazer sofrimento a estes seres ${ }^{354}$.

$\mathrm{O}$ crescente movimento espanhol por direitos para os animais tem pressionado o Estado a rever suas legislações, a fim de proibir condutas cruéis dirigidas aos não-humanos. A compreensão deste fenômeno tem motivado a discussão da matéria nos centros universitários.

Pesquisadores têm estudado os temas relacionados aos animais não-humanos tanto na perspectiva do direito (sensibilização das normas legais em vigor, análise de outras possibilidades de interpretação para solução de questões pendentes), quanto do aspecto da ética (discussão de argumentos éticos contra o abuso animal), de modo a considerar as razões que podem levar uma pessoa a ser cruel com um outro $\operatorname{ser}^{355}$.

O pensamento de que os animais não-humanos merecem consideração

${ }^{351}$ Cf. LEITE, Fátima Correia; NASCIMENTO, Esmeralda. Regime Jurídico dos Animais de Companhia. Coimbra, Almedina, 2004; De forma geral: SILVA, Vasco Pereira da. Verde Cor de Direito: Lições de Direito do Ambiente, Almedina, 2004. pp. 63-64.

${ }^{352}$ ARAÚJO, Fernando. The Recent Development of Portuguese Law in the Field of Animal Rights. Journal of Animal Law. Vol. 01. pp. 61-72. 2005. p. 64.

${ }^{353}$ GIMÉNEZ-CANDELA, María Teresa. New rules to ensure the protection of animals in Spain: Spanish Animal Welfare Act. 32/2007. Revista de Bioética y Derecho. No 14. pp. 2528. Septiembre, 2008. p. 26.

${ }^{354}$ MULÀ, Anna. La iniciativa legislativa popular de abolición de las corridas de toros en Cataluña. Revista de Bioética y Derecho. No 20. pp. 27-32. Septiembre, 2010. p. 27.

355 TAFALLA, Marta. La apreciación estética de los animales. Consideraciones estéticas y éticas. Revista de Bioética y Derecho. № 28. , pp. 72-90. Mayo, 2013. p. 74. 
moral e jurídica tem dominado os debates universitários espanhóis, na busca, cada vez mais intensa, de uma argumentação politicamente condizente para a resolução das demandas sociais emergentes ${ }^{356}$. Questões como o abandono de animais ${ }^{357}$ e a experimentação realizada em grandes primatas são umas das novas fronteiras que se busca ultrapassar no debate espanhol ${ }^{358}$.

Sendo assim, o Direito Animal Espanhol tem recebido um forte apoio de instituições norte-americanas e francesas, sendo atualmente o principal pólo difusor da matéria na Europa ${ }^{359}$. Desde 2011, a Universidade Autônoma de Barcelona oferece o único curso de pós-graduação em Direito Animal da Europa, o mestrado em Direito Animal e Sociedade chefiado pela Professora Teresa Giménez-Candela ${ }^{360}$.

O progresso espanhol tem sido possível graças às mudanças feitas na legislação europeia. Em 13 de dezembro de 2007, o Tratado de Lisboa, em seu artigo 13 , modificou a natureza jurídica dos animais, passando a considerá-los seres sencientes, merecedores de cuidado, e não mais coisas móveis, de modo que os países signatários da União Europeia tiveram cerca de dois anos para adaptar suas leis, promulgando legislações de defesa animal ${ }^{361}$.

${ }^{356}$ CASTELO, Carmen Velayos. Animales reales en el arte, o sobre los límites Ėticos de la capacidad creadora. Revista Brasileira de Direito Animal/Brazilian Animal Rights Review. Vol. 02. Ano. 1. Jan/Jun. p. 11-36. Salvador: Evolução, 2007. p. 21.

${ }^{357}$ LACABEX, María González. Sobre animales y desahucios. In Teresa Giménez-Candela. (Org.). dA derecho ANIMAL la web center de los animales con derecho. Barcelona: Universitat Autonoma de Barcelona, August 2012.

${ }^{358}$ TAFALLA, Marta. Sobre perros y justicia: a propósito de la prohibición del sacrificio de perros abandonados en Catalunya. Revista de Bioética y Derecho. No 06. pp. 01-05. Marzo, 2006. p. 02.

359 Em 2010, Professora Teresa Giménez-Candela fundou, com apoio da Universidade Autônoma de Barcelona, o sítio eletrônico: www.derechoanimal.info, o primeiro site da Espanha dedicado ao tema Direito Animal. Nele foi formado uma banco de dados sobre legislação e jurisprudência animal da Europa, fornecendo material didático e pedagógico aos profissionais europeus que queiram fazer parte deste projeto. Sobre o por quê estudar Direito Animal, ver: GIMÉNEZ-CANDELA, María Teresa. ¿Por qué estudiar Derecho Animal? In Teresa Giménez-Candela. (Org.). dA derecho ANIMAL la web center de los animales con derecho. Barcelona: Universitat Autonoma de Barcelona, October 2013. Disponível em: http:// www.derechoanimal.info/esp/page/2858/ipor-que-estudiar-derecho-animal. Acessado em: 10.10.2013.

${ }^{360}$ Ver o trabalho desenvolvido pela Professora Teresa Giménez-Candela junto a Universidade Autônoma de Barcelona em: http://www.derechoanimal.info/esp/page/1667/presentacion. Acessado em: 02.08.2013.

${ }^{361}$ Dispõe o Tratado de Lisboa (Tratado sobre o Funcionamento da União Europeia) em seu artigo 13 que: "na formulação e implementação de políticas de agricultura, pesca, transporte, mercado interno, pesquisa e desenvolvimento tecnológico e espaço, a União e os PaísesMembros devem considerar as necessidades de bem-estar dos animais, visto que os animais são seres sencientes, enquanto respeita as disposições e os costumes dos Países-Membros em 
A legitimação política e social do debate tem permitido o crescimento da pesquisa na área, em especial entre os operadores do direito. O Curso oferecido pela Universidade Autônoma de Barcelona adota uma metodologia pós-humanista e transdisciplinar ${ }^{362}$, a fim de realizar uma análise comparativa dos sistemas jurídicos internacionais em defesa do animal ${ }^{363}$. O programa estende-se para englobar questões sobre os novos modelos de integração das leis de proteção animal e sua análise constitucional, além de atividades práticas para que os estudantes possam vivenciar questões que envolvam os interesses dos animais e seu processo em juízo ${ }^{364}$.

Neste contexto, Jean-Pierre Marguénaud deu início, através do Observatório de Mudanças Institucionais do Direito (L'Observatoire des mutations institutionnelles et juridiques) da Universidade de Limoges/França ${ }^{365}$, em 2009, à publicação da Revista Semestral de Direito Animal (Revue Semestrielle de Droit Animalier) coordenada também pelos Professores Jacques Lero e Florence Burgat. A Revista francesa está dividida em duas partes, a primeira a tratar sobre questões jurídicas concernentes aos animais não-humanos de relevância da sociedade francesa e a segunda com o objetivo de trazer relatos ou reportagens especiais sobre temas diversos que envolvam os interesses dos animais, como, por exemplo, experimentação animal, touradas, maus-tratos dentre outros ${ }^{366}$.

Professores da Universidade de Limoges têm estabelecido uma parceria com universidades estrangeiras na Turquia, Bélgica, Itália, Grécia e, em especial, Espanha, por meio da Universidade Autônoma de Barcelona, o que tem incrementado as publicações relacionadas à temática do Direito Animal. Esta cooperação entre instituições de ensino já tem gerado efeitos positivos no sistema jurídico francês. A reforma do Código Civil francês traz mudanças no estatuto jurídico dos animais a fim

relação a rituais religiosos específicos, tradições culturais e herança regional."

362 Ver: FAZENDA, Ivani Catarina Arantes. Interdisciplinaridade: História, Teoria e Pesquisa. Campinas, Editora Papirus, 1994.

${ }^{363}$ Uma apresentação, a metodologia e os objetivos do curso podem ser encontrados em: http:/www.uab.es/servlet/Satellite/postgrau/master-en-dret-animal-i-societat-animal-law -and-society-/dades-basiques-1203328491238.html/param1-2826_ca/param2-2003/. Acessado em: 05.08.2013.

${ }^{364}$ Sobre o tema ver, dentre outros: SILVA, Tagore Trajano de Almeida. Capacidade de ser parte dos Animais Não-Humanos: Repensando os Institutos da Substituição e Representação Processual. In Teresa Giménez Candela. (Org.). dA derecho ANIMAL la web center de los animales con derecho. Barcelona: Universitat Autónoma de Barcelona, Septiembre, 2010.

365 Sobre do L'Observatoire des mutations institutionnelles et juridiques ver site do grupo de pesquisa em: http://www.unilim.fr/omij/rubriques/index.php?rubrique=13. Acessado em: 04.08.2013.

${ }^{366}$ A Revista Semestral de Direito Animal da França (Revue Semestrielle de Droit Animalier) tem acesso gratuito pelo site do grupo de pesquisa da Universidade de Limoges, estimulando a discussão em torno dos países de língua francesa. Sobre a Revista ver o site: http://www. unilim.fr/omij/rubriques/index.php?rubrique=42. Acessado em: 05.08.2013. 
de adequar os interesses dos não-humanos às reivindicações sociais da atualidade ${ }^{367}$.

$\mathrm{Na}$ esfera jurídica francesa avanços também têm sido propostos na direção da mudança do status jurídico dos animais. Atualmente, encontra-se no Parlamento o Projeto de Lei de $\mathrm{n}^{\circ} 4495$, reivindicando a criação de um livro específico no Código Civil para tratar dos animais. Este volume adequaria o Direito interno francês às diretivas da União Europeia, pois estabeleceria que os animais não-humanos são seres sensíveis, ocupando o espaço entre os homens e as coisas, mas não fazendo parte de nenhum deles ${ }^{368}$.

Com efeito, é na França que o debate sobre a personalidade jurídica dos animais encontra-se mais avançado. Percebeu-se logo o caráter ficcional e abstrato do conceito de personalidade jurídica atribuído pelo direito, estando o conceito relacionado aos interesses sociais, econômicos e culturais dos humanos. Como uma forma de resolver a questão, os pesquisadores franceses propõem uma personalidade animal (sui generis) a demonstrar a relevância dos não-humanos no sistema jurídi$\operatorname{co}^{369}$.

Para Olivier Le Bot, a França poderia absorver as experiências das Constituições de países como Brasil, Índia, Suíça, Alemanha e Luxemburgo, dirigindo uma proteção constitucional aos animais enquanto seres dotados de valor intrínseco, ou seja, na defesa do animais em $\mathrm{si}^{370}$. Normas constitucionais em favor dos animais é um fenômeno novo, advindo das Constituições que optam em seu texto por uma maior sensibilização e respeito em torno da vida do animal não-humano ${ }^{371}$.

Tal como ocorreu em outros países, o desenvolvimento do Direito Animal Francês conta com um forte movimento social em torno da questão. Na França, a Fundação Direito Animal, Ética e Ciências, sediada em Paris, é responsável pela publicação de periódico trimestral - Droit Animal, Éthique \& Sciences, com intuito de divulgar estudos multidisciplinares e reflexões sobre os novos conhecimentos científicos e desenvolvimentos éticos referentes à vida dos animais não-humanos ${ }^{372}$.

\footnotetext{
${ }^{367}$ ANTOINE, Suzanne. Le projet de réforme du droit des biens - Vers un nouveau régime juridique de l'animal? Revue Semestrielle de Droit Animalier - RSDA. Vol. 01. pp. 11-20. Jan/Juin, 2009. p. 12.

${ }^{368}$ NOUËT, Jean-Claude. Régime juridique de l'animal. Droit Animal, Éthique \& Sciences. $\mathrm{N}^{\circ}$ 74. Juillet, 2012. p. 04.

${ }^{369}$ Ver, dentre outros, MARGUÉNAUD, Jean-Pierre. La protection juridique du lien d'affection envers un animal, Dalloz 2004.

${ }^{370}$ LE BOT, Olivier. Direitos Fundamentais para os animais : uma ideia absurda ? Revista Brasileira de Direito Animal/Brazilian Animal Rights Review. Vol. 11. Ano 7. jul/dez. p. 3756. Salvador: Evolução, 2012. p. 44.

${ }^{371}$ LE BOT, Olivier. La protection de l'animal en droit constitutionnel. Etude de droit comparé. Lex Electronica. Vol. 12. N². pp. 01-54. Automne/Fall, 2007. pp. 03-04.

372 KEMP, Thierry Auffret Van Der. La Fondation LFDA: Qui? Pourquoi? Comment? Droit Animal, Éthique \& Sciences. N 75. Octobre, 2012. p. 04.
} 
Esta interação da Academia com o público através das publicações tem possibilitado uma maior sensibilização social do conteúdo produzido por estas instituições, conseguindo responder mais rapidamente às críticas contemporâneas do direito $^{373}$.

Juristas ingleses, norte-americanos, portugueses, espanhóis e franceses têm corroborado com o desenvolvimento de uma nova perspectiva em torno da vida humana e não-humana. Pesquisadores do campo do Direito Animal buscam expandir o círculo moral e jurídico para abraçar os interesses dos animais não-humanos. Pode-se dizer que este trabalho fadigoso de vanguarda tem colaborado para mudanças metodológicas, filosóficas e jurídicas dentro das Faculdades de Direito. Como visto, o incremento do Direito Animal tem colaborado para o desenvolvimento da ciência jurídica e de seus programas de pós-graduação, capacitando novos intelectuais e esperando deles um repensar dos velhos conceitos clássicos do direito.

Dentro do panorama mundial, o Brasil desponta como país que mais vem desenvolvendo o estudo da área, sendo momento de avançar para a criação de uma nova disciplina que através de uma perspectiva pós-humanista concretize os anseios da Constituição Federal.

\section{A EXPERIÊNCIA BRASILEIRA}

O processo de redemocratização brasileiro trouxe consigo uma nova Carta Política aberta para os problemas de seu tempo. Com o advento da Constituição de 1988 foi possível repensar a forma de tratamento dos não-humanos, tendo as Faculdades de Direito desempenhado um papel importante na conscientização da sociedade sobre a questão. A defesa de uma cadeira específica de Direito Animal nas instituições de direito é a resposta dada pelos próprios estudantes na tentativa de pós-humanizar um curso em crise. A conjuntura encontrada nestas instituições demonstra que há um lapso entre as expectativas sociais dos discentes e as práticas pedagógicas oferecidas em sala de aula ${ }^{374}$.

Boaventura de Souza Santos, ao analisar este contexto, assevera que "as crises de crescimento têm lugar ao nível da matriz disciplinar de um dado ramo da ciência, isto é, revelam-se na insatisfação perante métodos ou conceitos básicos até então usados sem qualquer contestação na disciplina" ${ }^{375}$. O desconhecimento e a

\footnotetext{
${ }^{373}$ MARGUÉNAUD, Jean-Pierre. Proposition pour surpasser la division des associations de protection des animaux. Revue Semestrielle de Droit Animalier-RSDA. Vol. 02. pp. 21-25. Juil/Déc, 2012. pp. 21-22.

${ }^{374}$ Sobre uma crítica do ensino jurídico, ver: FARIA, José Eduardo. A Noção de Paradigma na Ciência do Direito: notas para uma crítica ao idealismo jurídico. In: FARIA, José Eduardo. (org). A Crise do Direito numa Sociedade em Mudança. Brasília: Editora UnB, 1988. pp. 14-30.

${ }^{375}$ SANTOS, Boaventura de Sousa. Introdução a uma ciência pós-moderna. Rio de Janeiro,
} 
má-formação teórica produzida por este modelo que não quer se renovar compromete sensivelmente a compreensão da ciência do direito, limitando o aluno a propor diferente do normal, a inovar.

Sendo assim, a experiência brasileira do ensino do Direito Animal iniciouse através de um revezar de crítica, ridicularização e bastante ironia em torno dos profissionais que despendiam sua energia, tempo e orçamento na defesa dos animais. Não é novidade a colocação de estereótipos em sociedades competitivas e espetacu$\operatorname{losas}^{376}$ como a brasileira ${ }^{377}$. Entretanto, durante longos anos, defensores dos animais foram vistos como misantropos, elitistas e até mesmo, alternativos, pois para muitos a bandeira do Direito Animal era inadmissível dentro de uma sociedade com tantos problemas sociais a serem resolvidos. ${ }^{378}$

Parece que há uma disputa velada para se dizer o direito, o que é certo ou errado, quais as lutas importantes e quais não são e, principalmente, quem são os protagonistas e quando se devem travar estas disputas ${ }^{379}$.

Por este motivo, intelectuais e seus centros de pesquisa ignoravam a relação da fome, da pobreza, da miséria, da violência e da crueldade com a instrumentalização dos animais ${ }^{380}$. Na sociedade atual, a situação agrava-se, já que em muitas comunidades, onde as relações familiares de trabalho, de produção, de amizade bem como as relações amorosas estão sendo deterioradas, o convívio entre humanos e não-humanos serve como última forma de esteio social ${ }^{381}$.

No Brasil, uma das últimas fronteiras a ser abolida é a da negação de valor intrínseco aos animais. Ainda se lamenta o fato de que durante séculos o Estado brasileiro e seus "cidadãos" sacrificaram uma quantidade inestimável de indivíduos escravos, estrangeiros, índios, pobres, mulheres e crianças para uma finalidade pessoal $^{382}$. O momento é de avançar aprendendo com os erros passados, reconhecendo o

Graal, 1989. p. 18.

${ }^{376}$ Para uma crítica a realidade espetaculosa produzida nas sociedades ocidentais, ver: DEBORD, Guy. A Sociedade do Espetáculo. Rio de Janeiro: Contraponto, 1997. p. 131.

${ }^{377}$ Cf. DAMATTA, Roberto. Carnavais, Malandros e Heróis. Rio de Janeiro: Rocco, 1997. pp. 171 e ss.

${ }^{378}$ REGAN, Tom. The Case for Animal Rights. In: Peter Singer (ed), In Defense of Animals. New York: Basil Blackwell, 1985, pp. 13-26. p. 24. Em português, REGAN, Tom. A causa dos direitos dos animais. Revista Brasileira de Direito Animal. Vol. 08. № 12. Jan/abr. 2013. p. 35 .

${ }^{379}$ BOURDIEU, Pierre. O Poder Simbólico. 6. ed. Rio de Janeiro: Bertrand Brasil, 2003. p. 75 e ss.

${ }^{380}$ Sobre a temática da fome e da pobreza, ver: SINGER, Peter. Famine, Affluence, and Morality. Philosophy and Public Affairs. Vol. 01. n. 01. pp. 229-243. Spring, 1972.

${ }^{381}$ Cf. DUCKLER, Geordie. The Economic Value of Companion Animals: A Legal and Anthropological Argument for Special Valuation. Animal Law. Vol. 08. pp. 199-221. 2002.

${ }^{382}$ Cf. GORDILHO, Heron José de Santana. Abolicionismo Animal. Salvador: Evolução, 
fim do muro ficcional entre humanos e não-humanos que insiste em existir. ${ }^{383}$

A construção de um caminho viável passa tanto pelas vias institucionais (Executivo, Legislativo e Judiciário) como também por meio da sensibilização dos principais atores deste processo. No Brasil, vários são os responsáveis por desenvolver uma opção positiva na defesa dos animais e de seus interesses juridicamente protegidos. O papel de cada um deles será fundamental para a construção de um modelo brasileiro do curso de Direito Animal.

\subsection{ENSINO do DIREITO ANIMAL E SEUS PROFESSORES}

A trajetória brasileira de ensino do Direito Animal é recente e se relaciona com o processo de redemocratização brasileiro. Em geral, com a promulgação da Constituição de 1988, tornou-se necessário reestruturar o ensino do direito no país como resultado de mudanças sociais e jurídicas trazidas pela nova ordem. ${ }^{384}$

O papel de reorganização das bases do ensino jurídico foi, inicialmente, pensado para solucionar os conflitos humanos, apaziguando o contexto social de mudança pelo qual passava o Estado brasileiro. Nesta esteira, o ensino do Direito Animal apenas se tornou possível no momento em que alguns professores e pesquisadores, resolveram levantar a questão, evidenciando um cenário moral e jurídico incongruente com a vida dos animais. Até hoje, não-humanos são vistos como produto a serem comercializados e utilizados pelos seus detentores, nada se questionando sobre uma vida autônoma desses seres ou mesmo pelos avanços científicos das outras áreas do saber. O direito seguia seu trajeto, olhando apenas para os interesses de quem o produzia.

Com efeito, esta visão narcisista do direito foi questionada por advogados e ativistas que participaram destas lutas sociais e que logo após ingressaram em instituições de ensino do direito, tornando-se professores. Edna Cardozo Dias foi a primeira docente a reivindicar uma tutela jurídica para os animais ainda em 2001 na Pontifícia Universidade Católica de Minas Gerais - PUC/MG quando ministrou o curso "Tutela Jurídica dos Animais" por dois semestres ${ }^{385}$. Edna Cardozo partici-

2009.

${ }^{383}$ WISE, Steven M. Animal Thing to Animal Person - Thoughts on Time, Place, and Theories. Animal Law. Vol. 05. pp. 61-68. 1999. p. 61.

${ }^{384}$ Ver, de forma geral, FARIA, José Eduardo. A Noção de Paradigma na Ciência do Direito: notas para uma crítica ao idealismo jurídico. In: FARIA, José Eduardo. (org). A Crise do Direito numa Sociedade em Mudança. Brasília: Editora UnB, 1988. pp. 14-30.

${ }^{385}$ Deve-se destacar o trabalho realizado por Laerte Levai (LEI/USP) que desde a década de 1990 atua no campo do Direito Animal, escrevendo o primeiro livro de língua portuguesa voltado para o tema, bem como operando na formação dos novos pesquisadores. Para Levai, o currículo do curso de Direito Animal deveria ser dividido em três grandes grupos: 1) Filosófico; 2) Jurídico; e 3) Pedagógico, evidenciando uma transdisciplinaridade desta nova disciplina. Cf. LEVAI, Laerte Fernando. Direito dos animais. O direito deles e o nosso direito 
pou do processo de constitucionalização de direitos para os animais ainda em 1987, sendo fundadora da Liga de Prevenção de Crueldade contra o Animal, entidade que representou o debate animal durante a Assembleia Constituinte, propondo emendas ao texto final da Constituição ${ }^{386}$.

Edna Cardozo elaborou um plano de aula, onde os elementos sociais relacionados aos animais fossem importantes, dando ênfase ao movimento de proteção animal $^{387}$, convidando outros dois professores (Flávio Augusto Salim Nogueira, no primeiro semestre, e Regina Bueno, no segundo) a dividir a sala de aula com ela. O objetivo era criar uma disciplina multidisciplinar, em que um professor abordaria os avanços científicos e o outro as repercussões jurídicas de cada tema. Esta metodologia criou um cenário estimulante para que novos docentes buscassem novas perspectivas $^{388}$.

Realmente, em 2003, Danielle Tetü Rodrigues inicia o magistério do curso "Relação entre o Homem e a Natureza", na Pontifícia Universidade Católica do Paraná - PUC/PR, onde trata de questões dos não-humanos. Como um módulo dentro da especialização lato sensu em Direito Ambiental, Danielle Rodrigues destacou-se pioneiramente ao lecionar para profissionais do direito, publicando livro e artigos com intuito de ampliar o acesso às informações sobre uma perspectiva ética e jurídica dos animais de forma individualizada ${ }^{389}$.

Logo após, influenciado pelos estudos do doutorado na Universidade Federal de Pernambuco, Heron Gordilho propôs o curso de "Ética e Direitos dos Animais" como extensão universitária, voltado para a educação ambiental em escolas públicas ${ }^{390}$. O objetivo era vincular o ensino e a pesquisa em diversos níveis de educação formal e não-formal, possibilitando o desenvolvimento de uma nova perspectiva em torno dos animais ${ }^{391}$.

sobre eles. Campos do Jordão: Editora Mantiqueira, 1998.

${ }^{386}$ DIAS, Edna Cardozo. A Defesa dos animais e as conquistas legislativas do movimento de proteção animal no Brasil. Revista Brasileira de Direito Animal. Vol. 02. n. 1. jan/jun. p. 123-142. Salvador: Evolução, 2007. p. 134.

${ }^{387}$ Sobre o trabalho da professora, ver: DIAS, Edna Cardozo. A tutela jurídica dos animais. Belo Horizonte: Mandamentos, 2000.

${ }^{388}$ Por exemplo, em 2001, foram organizados Congressos de defesa da fauna, em Brasília, pelo Conselho da Justiça Federal e por Heron Gordilho e Luciano Santana na UFBA. Esta visão apenas foi substituída pela de direitos para os animais, em 2008, com os Congressos Mundiais de Bioética e Direito dos Animais, como se verá na sessão seguinte. Sobre os congressos, ver: www.abolicionismoanimal.org.br. Acessado em: 01.08.2013.

${ }^{389}$ Cf. RODRIGUES, Danielle Tetü. O Direito \& os Animais: uma abordagem ética, filosófica e normativa. Curitiba: Juruá, 2003.

${ }^{390}$ Sobre o trabalho realizado na UFBA, conferir informações em: http://www.direito.ufba. br/interna.php?cod=46. Acessado em: 15.08.2013.

${ }^{391}$ Exemplo da atividade pode ser encontrado em: AMORIM, Fernando. Humanos são enjaulados no zoológico de Salvador. In: A Tarde. Publicado em: 13 de Outubro de 2008. 
Heron Gordilho buscou uma reflexão crítica dos fatores políticos, econômicos, ecológicos e jurídicos que sustentavam a exploração institucionalizada dos animais na sociedade contemporânea, trabalhando de forma transdisciplinar com estudantes da graduação de diversos cursos: jornalismo, medicina veterinária, direito, biologia dentre outros; contando com o apoio da Professora de jornalismo Simone Bortoliero. A proposta partia do pressuposto de que os animais são sujeitos de direito, devendo o sistema jurídico considerar esta real situação.

Em 2008, Fábio Corrêa de Oliveira, ainda professor da Universidade Federal Rural do Rio de Janeiro (UFRRJ) e Daniel Braga Lourenço atual professor da instituição ao participar do processo de elaboração do curso de direito, inseriram como disciplina obrigatória o componente curricular "Direito dos Animais" a ser lecionada no último ano na etapa de especialização em Direito Ambiental, porém a disciplina foi excluída na reforma de ensino da faculdade ${ }^{392}$. Atualmente, as questões dos animais tem sido objeto de estudo na matéria "Ética Ecológica", obrigatória na especialização em Direito Ambiental da graduação na UFRRJ ${ }^{393}$.

Ainda no Rio de Janeiro ${ }^{394}$, por iniciativa do Fábio de Oliveira, a Escola de Ciências Jurídicas da Universidade Federal do Estado do Rio de Janeiro (UNIRIO) tem disponibilizado aos seus estudantes de mestrado e graduação a disciplina "Direito dos Animais e Ecologia Profunda", possibilitando uma inter-relação dos temas ambientais com o discurso animalista, além de corroborar com uma formação multidisciplinar de seu corpo discente ${ }^{395}$.

Dentre os programas de pós-graduação, pode-se também citar o trabalho feito por Fernanda Medeiros, ao adotar a disciplina "Direito dos Animais" no mestrado na Faculdade de Direito da Universidade Caxias do Sul ${ }^{396}$ e Heron Gordilho ao oferecer o curso "Estudos aprofundados de bioética e de direitos dos animais" como componente da grade curricular da linha de pesquisa de mesmo nome adotada pelo curso de pós-graduação stricto sensu (mestrado e doutorado) da Faculdade de

${ }^{392}$ OLIVEIRA, Fábio Corrêa Souza de. Direitos da Natureza e Direito dos Animais: Um Enquadramento. Revista do Instituto do Direito Brasileiro da Faculdade de Direito da Universidade de Lisboa-RIDB. Vol. 10. pp. 11325-11370. 2013. p. 11346.

${ }^{393}$ Cf. LOURENÇO, Daniel. Direito dos Animais: fundamentação e novas perspectivas. Porto Alegre: Sergio Antonio Fabris, 2008.

${ }^{394}$ No âmbito da pós-graduação lato sensu, Mery Chalfun tem se destacado ao relacionar o direito animal com a bioética, orientando estudantes e profissionais do direito sobre o importância de uma educação voltada ao cuidado dos animais. Ver, sobre o trabalho da autora: CHALFUN, Mery. Paradigmas filosóficos - ambientais e o direito dos animais. Revista Brasileira de Direito Animal. Vol. 06. pp. 209-246. Jan/Jun. Salvador: Evolução, 2010.

${ }^{395}$ OLIVEIRA, Fábio Corrêa Souza de. Direitos da Natureza e Direito dos Animais: Um Enquadramento. Revista do Instituto do Direito Brasileiro da Faculdade de Direito da Universidade de Lisboa - RIDB. Vol. 10. pp. 11325-11370. 2013. p. 11346.

${ }^{396}$ Cf. MEDEIROS, Fernanda Luiza Fontoura de. Direito dos animais. Porto Alegre: Livraria do Advogado, 2013. 
Direito da Universidade Federal da Bahia ${ }^{397}$.

\subsection{OS GRUPOS DE PESQUISA E EXTENSÃo EM DIREITO ANIMAL}

O progresso dos estudos acadêmicos no campo de interesse do Direito Animal tem colaborado para o surgimento de pesquisadores jusanimalistas, a defender uma autonomia das questões relacionadas aos animais não-humanos.

$\mathrm{O}$ reconhecimento de um objeto próprio, de um método a ser percorrido e de uma teoria a ser revisada serviu como terreno fértil a ser cultivado por diversos pesquisadores, tais como: Laerte Levai ${ }^{398}$, Edna Cardozo Dias ${ }^{399}$, Heron Gordilho ${ }^{400}$, Luciano Santana ${ }^{401}$, Danielle Tetü Rodrigues ${ }^{402}$, Daniel Lourenço ${ }^{403}$, Vânia Tuglio ${ }^{404}$, Fábio de Oliveira ${ }^{405}$, Fernanda Medeiros ${ }^{406}$, Diomar Ackel Filho ${ }^{407}$, Anaiva Oberst ${ }^{408}$,

397 Cf. GORDILHO, Heron José de Santana. Abolicionismo Animal. Salvador: Evolução, 2009.

${ }^{398}$ Cf. LEVAI, Laerte Fernando. Direito dos animais. O direito deles e o nosso direito sobre eles. Campos do Jordão: Editora Mantiqueira, 1998.

${ }^{399}$ Cf. DIAS, Edna Cardozo. A tutela jurídica dos animais. Belo Horizonte: Mandamentos, 2000 .

${ }^{400}$ Cf. GORDILHO, Heron José de Santana. Abolicionismo Animal. Salvador: Evolução, 2009.

401 Cf. SANTANA, Luciano Rocha \& SANTOS, Clarissa Pereira Gunça dos. O crime de maus-tratos aos animais: uma abordagem sobre a interpretação e a prova de materialidade e autoria (artigo 32). In MARCHESAN, Ana Maria Moreira \& STEIGLEDER, Annelise Monteiro. (org.). Crimes Ambientais Comentários à Lei 9.605/98. Porto Alegre: Livraria do Advogado, 2013.

${ }^{402}$ Cf. RODRIGUES, Danielle Tetü. O Direito \& os Animais: uma abordagem ética, filosófica e normativa. 2. ed. Curitiba: Juruá, 2008.

${ }^{403}$ Cf. LOURENÇO, Daniel. Direito dos Animais: fundamentação e novas perspectivas. Porto Alegre: Sergio Antonio Fabris, 2008.

${ }^{404}$ Cf. TUGLIO, Vânia. Rodeios e crueldade contra animais. Revista de Direito Ambiental. Vol. 10. 2005.

${ }^{405}$ Cf. OLIVEIRA, Fábio Corrêa Souza de. Direitos da Natureza e Direito dos Animais: Um Enquadramento. Revista do Instituto do Direito Brasileiro da Faculdade de Direito da Universidade de Lisboa-RIDB. Vol. 10. pp. 11325-11370. 2013. p. 11346.

${ }^{406}$ Cf. MEDEIROS, Fernanda Luiza Fontoura de. Direito dos animais. Porto Alegre: Livraria do Advogado, 2013.

${ }^{407}$ Cf. ACKEL FILHO, Diomar. Direito dos Animais. São Paulo: Themis Livraria, 2001.

${ }^{408}$ Cf. OBERST, Anaiva. Direito Animal. Rio de Janeiro: Lumen Iuris, 2012. 
Vânia Nogueira ${ }^{409}$, Cleopas Santos, Thiago Pires ${ }^{410}$, Mery Chalfun ${ }^{411}$, Selma Mandruca, Renata Martins ${ }^{412}$, Vânia Rall ${ }^{413}$, Tiago Fensterseifer ${ }^{414}$, Alfredo Migliore ${ }^{415}$, Anderson Furlan ${ }^{416}$, Jaime Chatkin, Letícia Albuquerque, dentre outros ${ }^{417}$.

O progresso científico desse campo de pesquisa tem características próprias, uma vez que conta com o apoio institucional das Universidades Federais e de grupos interessados da sociedade civil. Este diálogo entre o conhecimento formal e informal, desenvolvido pelos jusanimalistas evidencia o caráter plural da disciplina e traz novas alternativas para o ensino do direito.

Desta forma, pode-se dizer que uma das primeiras instituições a fomentar o debate acadêmico foi a Sociedade Vegetariana Brasileira (SVB), fundada em 16 de agosto de 2003 por Marly Winckler, com o objetivo de difundir a filosofia vegetariana de respeito pelos animais ${ }^{418}$. Desde 2006, a SVB vem organizando palestras, seminários, debates sobre a temática dos animais, inclusive no campo político e jurídico, colaborando para o amadurecimento das questões referentes a estes seres ${ }^{419}$.

${ }^{409}$ Cf. NOGUEIRA, Vânia Márcia Damasceno. Direitos Fundamentais dos Animais: a construção jurídica de uma titularidade para além dos seres humanos. Belo Horizonte: Arraes Editores, 2012.

${ }^{410}$ Cf. OLIVEIRA, Thiago Pires. Redefinindo o Status jurídico dos animais. Revista Brasileira de Direito Animal. Vol. 03. jul/dez. 2007.

${ }^{411}$ Cf. CHALFUN, Mery. Paradigmas filosóficos - ambientais e o direito dos animais. Revista Brasileira de Direito Animal. Vol. 06. pp. 209-246. Jan/Jun. Salvador: Evolução, 2010.

${ }^{412}$ Cf. MARTINS, Renata de Freitas. O respeitável público não quer mais animais em circos! Revista Brasileira de Direito Animal. Vol. 03. n.04. jan/dez. Salvador: Evolução, 2008.

${ }^{413}$ Cf. LEVAI, Laerte Fernando \& DARÓ. Vânia Rall, Experimentação animal: histórico, implicações éticas e caracterização como crime ambiental. Revista de Direito Ambiental. São Paulo, Revista dos Tribunais, n. 36, out./dez., 2004.

${ }^{414}$ Cf. FENSTERSEIFER, Tiago. Direitos Fundamentais e Proteção do Ambiente: a dimensão ecológica da dignidade humana no marco jurídico-constitucional do Estado Socioambiental de Direito. Porto Alegre: Livraria do Advogado, 2008.

415 Cf. MIGLIORE, Alfredo Domingues Barbosa. Personalidade Jurídica dos Grandes Primatas. Belo Horizonte: Del Rey, 2012.

${ }^{416}$ Cf. FURLAN, Anderson \& FRACALOSSI, William. Direito ambiental. Rio de Janeiro: Forense, 2010.

${ }^{417}$ Por se tratar de um ensino transdisciplinar, profissionais de diversas áreas têm participado da construção do curso de Direito Animal, destacando-se os trabalhos de: Paula Brügger (UFSC), Rita Paixão (UFF), Carlos Naconecy (PUC/RS), Ariene Bassoli (UFPE), Sônia Felipe (UFSC), Maria Clara Dias (UFRJ), Simone Lima (UnB), Marcelo Pelizzoli (UFPE), Anamaria Feijó (PUC/RS), dentre outros.

${ }^{418}$ Para maiores informações visitar o site: http://www.svb.org.br. Acessado em: 01.08.2013.

${ }^{419}$ A Universidade de São Paulo (USP), através do Laboratório de Estudos sobre a Intolerância da Faculdade de Filosofia, Letras e Ciências Humanas (LEI), tem promovido seminários anuais para tratar da temática e desenvolver a questão dos animais. Dentre seus membros 
A partir dos ensinamentos colhidos no I Congresso Vegetariano Brasileiro e Latino-americano organizado pela SVB no Memorial da América Latina em São Paulo que o Instituto Abolicionista pelos Animais (IAA) pôde ser criado ${ }^{420}$.

Idealizado por juristas, filósofos, veterinários, biólogos e ecologistas ${ }^{421}, \mathrm{o}$ IAA uniu ao direito, o conhecimento transdisciplinar das demais disciplinas com o objetivo de dar suporte jurídico e fundamentação filosófica, bem como apoio técnico na formulação e ajuizamento de ações em defesa dos interesses dos animais. Como resultado deste encontro, foi publicada a primeira edição da Revista Brasileira de Direito Animal, periódico pioneiro sobre o tema na América Latina ${ }^{422}$.

O Instituto Abolicionista pelos Animais teve papel decisivo na criação de uma cultura acadêmica em prol dos animais não-humanos. Foi ele o responsável por incrementar o discurso jurídico em favor dos animais e a inserção do tema em programas de pós-graduação em Direito do Brasil ${ }^{423}$. O intercâmbio com a Universidade Federal da Bahia fez surgir também o "Núcleo Interdisciplinar de Pesquisa e Extensão em Direitos dos Animais, Meio Ambiente e Pós-modernidade" - NIPEDA ${ }^{424}$.

Em 2008, como resultado da parceria entre as duas instituições foi realizado o I Congresso Mundial de Bioética e Direito Animal, com a participação dos professores Steven Wise, David Favre, Peter Singer, Gary Francione, Maria do Céu e Marti Keel, além de mais de trinta palestrantes nacionais e da Ministra Eliana Calmon. A repercussão do evento gerou resultados sólidos como a criação da linha de pesquisa em Bioética e Direito Animal no programa de pós-graduação em Direito da

estão Vânia Rall e Laerte Levai. Sobre o trabalho do LEI, ver o site: http://diversitas.fflch. usp.br/node/3215. Acessado em: 05.08.2013.

${ }^{420}$ Sobre as informações o evento, ver histórico no site da instituição em: http://www.svb.org. br/cvb/. Acessado em: 01 .08.2013.

${ }^{421}$ Dentre os participantes, pode-se citar: Heron Gordilho, Laerte Levai, Luciano Santana, Paula Brügger, Sônia Felipe, Vânia Rall, Carlos Naconecy, Marly Winckler, Tâmara Bauab, Mariângela Freitas, Rafael Mendonça, dentre outros.

${ }^{422}$ A Revista Brasileira de Direito Animal é publicada em convênio com a Michigan State University e a Universidade Federal da Bahia, contando com a versão digital gratuita para acesso dos usuários em: www.animallaw.info\#international, além do site www.rbda.ufba.br.

${ }^{423} \mathrm{O}$ Instituto Abolicionista pelos Animais (IAA) tem organizado os principais eventos na área do Direito Animal do país, contando a parceria de instituições privadas e universidades nacionais e estrangeiras. O objetivo é dar suporte filosófico e jurídico aqueles interessados na matéria. Sobre o IAA, ver o site: www.abolicionismoanimal.org.br. Acessado em: 03.08.2013.

${ }^{424}$ O Núcleo Interdisciplinar de Pesquisa e Extensão em Direitos dos Animais, Meio Ambiente e Pós-modernidade (NIPEDA) foi criado com o objetivo de encorajar a pesquisa no campo do Direito Animal e Bioética, sendo responsável por linha de pesquisa no programa de pós-graduação da UFBA. Sobre o núcleo, visitar: www.nipeda.direito.ufba.br/. Acessado em: 03 .08.2013. 
Universidade Federal da Bahia no ano seguinte ${ }^{425}$.

Pode-se dizer que em pouco tempo, a Bahia tornou-se o pólo de desenvolvimento da matéria, articulando outro Congresso Mundial em 2010, bem como desenvolvendo dentro do seu programa de pós-graduação linhas de pesquisa a gerar um intercâmbio cultural com universidades estrangeiras como a Michigan State University, a Universidade Autônoma de Barcelona e a Pace Law School.

A expansão da temática fez surgir, em 2010, na cidade do Rio de Janeiro, o "Centro de Direito dos Animais e Ecologia Profunda", grupo de pesquisa vinculado à Universidade Federal do Rio de Janeiro. O Centro foi pensado para abranger um discurso transdisciplinar, englobando docentes da Universidade Federal Rural do Rio de Janeiro e da Universidade Federal Fluminense. Esta articulação de saberes fez com que no mesmo ano fosse aprovado por órgão de fomento oficial $(\mathrm{CNPq})$ primeiro projeto institucional na área de Direito Animal. O grupo é responsável pela edição da Revista de Direito dos Animais e Ecologia Profunda, realizando anualmente o Encontro Carioca de Direito dos Animais (ECADIA) ${ }^{426}$.

O fortalecimento do debate nacional permitiu que, em 2011, fosse realizado o I Congresso Brasileiro de Bioética e Direito dos Animais, trazendo para a discussão a Ordem dos Advogados do Brasil (OAB). O reconhecimento da importância da questão pela $\mathrm{OAB}$ pressiona à Academia a sistematizar a matéria, oferecendo aos operadores do direito o conteúdo no qual possam intervir profissionalmente. Ademais, com o apoio da Ordem dos Advogados comissões de Direito Animal têm sido criadas nas seccionais do país, desenvolvendo formas de ensino alternativas para se ministrar o conteúdo referente aos animais.

Em 2012, o III Congresso Mundial realizado na Universidade Federal de Pernambuco contou com o apoio de membros do Poder Legislativo estadual e federal, demonstrando o importante papel que o discurso político tem na consideração do Direito Animal ${ }^{427}$.

Os jusanimalistas brasileiros têm contribuído para o progresso e reformulação dos currículos das Faculdades de Direito do Brasil, reinventando o dizer constitucional que afirma que o ensino, a pesquisa e a extensão são indissociáveis. $\mathrm{O}$ ensino jurídico proposto por estes profissionais transforma a maneira de pensar o direito posto, buscando novas alternativas, possibilidades, entendimentos que serão importantes tanto para a defesa do animal não-humano, quanto para o humano. $\mathrm{O}$

${ }_{425}$ Sobre o avanço do direito animal no Brasil, ver: SILVA, Tagore Trajano de Almeida. Brazilian Animal Law Overview: Balancing Human and Non-Human Interests. Journal of Animal Law. Vol. 06. pp. 81-104. 2010; do mesmo autor: Animais em juízo: direito, personalidade jurídica e capacidade processual. Salvador: Evolução, 2012.

${ }^{426}$ Mais informações sobre o grupo, visitar: www.animaisecologia.com.br. Acessado em: 01.08.2013.

${ }^{427}$ Sobre os congressos de Direito Animal realizados no Brasil, visitar o site do Instituto Abolicionista pelos Animais em: www.abolicionismoanimal.org.br. Acessado em 03.08.2013. 
próximo estágio é o da formação de uma base política sólida, a fim de gerar uma efetiva mudança legislativa em torno desses seres e, assim, a concretização do Direito Animal.

Nessa direção, durante o ano de 2013, foram organizados eventos, tendo como enfoque a necessidade de mobilização do Poder Legislativo em torno da questão dos animais. O encontro temático intitulado "Enfoque Político-Jurídico da Defesa dos Animais criados para consumo" ${ }^{428}$ realizado em Brasília pela Sociedade Vegetariana Brasileira e o II Congresso Brasileiro de Bioética e Direito dos Animais, sediado em Porto Alegre ${ }^{429}$, sob a organização do Instituto Abolicionista dos Animais demonstram que o caminhar tem sido constante na direção da ampliação de direitos no Brasil ${ }^{430}$.

\section{Conclusão}

Ao final do presente artigo, em que se evidenciou o panorama mundial do ensino do Direito Animal como disciplina autônoma, demonstrando o processo de formação e autonomia da disciplina e seus principais atores e instituições, é possível enunciar, objetivamente, algumas conclusões que sintetizam as ideias desenvolvidas.

1. A Universidade de Oxford foi o berço para o surgimento do movimento de libertação animal, pois foi nos seus corredores que professores e estudantes começaram a criar uma teoria que considerasse moralmente os interesses dos animais não-humanos;

2. O grupo de Oxford foi protagonista de uma série de mudanças filosóficas, jurídicas e éticas em torno dos animais, sendo responsáveis por estabelecer uma inter-relação entre o conhecimento acadêmico e as demandas sociais.

3. O envolvimento de instituições como a Ordem dos Advogados do Brasil, Universidade Federais, Instituto Abolicionista pelos Animais e a publicação de periódicos na área de Direito Animal encorajaram centros de pesquisa, estudantes e profissionais do direito a desenvolver este campo do conhecimento.

4. O currículo de Direito Animal foi pensado a oferecer aos alunos as mais diversas perspectivas do tratamento animal, de forma a não priorizar correntes filosóficas ou abordagens pessoais, avançando as discussões do campo teórico e filosófico para debates práticos e jurídicos em torno dos problemas que poderiam ser

428 Visitar site do evento em: http://www.svb.org.br/politicojuridico/. Acessado em: 03.09.2013.

429 A Pontifícia Universidade Católica do Rio Grande do Sul tem organizado anualmente um ciclo de palestras sobre Direito Animal, através do grupo chefiado por Fernanda Medeiros. Sobre o tema, ver: http://www.pucrs.br/eventos/direitodosanimais/. Acessado em: 03.10.2013.

${ }^{430}$ Sobre o evento, informações em: http://www.pucrs.br/eventos/direitodosanimais/. Acessado em: 03.10.2013. 
encontrados durante o aprendizado profissional dos alunos.

5. Direito Animal como componente curricular deve tratar de temas como: a) o movimento pelos direitos dos animais; b) o desenvolvimento das leis anticrueldade; c) avanço das legislações estaduais e federais; d) experimentação e vivissecção animal; e) animais usados como entretenimento, para fins religiosos ou para fins educativos; f) abate humanitário, dentre outros.

6. O currículo plural de Direito Animal possibilita ao estudante desenvolver um raciocínio, levando em consideração os interesses dos animais não-humanos através de uma abordagem diferenciada para cada nível de instrução. Na graduação, o curso oferecido deve conter um panorama geral dos temas de Direito Animal, sendo a disciplina oferecida nos primeiros anos do curso de direito. Já na pós-graduação, há a possibilidade de aprofundamento de cada um dos tópicos do panorama visto na graduação, aprofundando temas no campo da filosofia, epistemologia, teoria geral e da dogmática animal.

7. As instituições brasileiras têm participado para o progresso e reformulação dos currículos das Faculdades de Direito do Brasil, reinventando o dizer constitucional que afirma que o ensino, a pesquisa e a extensão são indissociáveis. Desse modo, a academia tem avançado na direção do paradigma pós-humanista de consideração jurídica dos animais não-humanos.

\section{REFERÊNCIAS}

ACKEL FILHO, Diomar. Direito dos Animais. São Paulo: Themis Livraria, 2001.

AMORIM, Fernando. Humanos são enjaulados no zoológico de Salvador. In: A Tarde. Publicado em: 13.10.008.

ANDRZEJEWSKI, Julie. Teaching Animal Rights at the University: Philosophy and Practice. Journal for Critical Animal Studies. Vol. 01. pp. 01-12. 2003.

ANTOINE, Suzanne. Le projet de réforme du droit des biens - Vers un nouveau régime juridique de l'animal? Revue Semestrielle de Droit Animalier - RSDA. Vol. 01. pp. 11-20. Jan/Juin, 2009.

ARAÚJO, Fernando. A Hora dos Direitos dos Animais. Coimbra: Almedina, 2003.

. The Recent Development of Portuguese Law in the Field of Animal Rights. Journal of Animal Law. Vol. 01. pp. 61-72. 2005.

BARTLETT, Steven J. Raízes da resistência humana aos direitos dos animais: Bloqueios psicológicos e conceituais. Revista Brasileira de Direito Animal. Salvador: Evolução, Vol.2, n.3, pp. 17-66, jul./dez. 2007.

. Roots of Human Resistance to Animal Rights: Psychological and Conceptual Blocks. Animal Law, v. 8, pp. 143-176 (2002). 
BENTHAM, Jeremy. An Introduction to the Principles of Morals and Legislation. London: W. Pickering, Linconln's inn fields and E. Wilson, Royal Exchange, 1823.

BORJA-SANTOS, Romana. Sintra proíbe touradas e espectáculos de circo com animais. Portugal. Publicado em: 27/04/2009 às 16:58h. Disponível em: http:/www. publico.pt/sociedade/noticia/sintra-proibe-touradas-e-espectaculos-de-circo-com -animais-1377028. Acessado em: 01.08.2013.

BOURDIEU, Pierre. O Poder Simbólico. 6. ed. Rio de Janeiro: Bertrand Brasil, 2003.

BROPHY, Brigid. The rights of animals. Sunday Times. Published in 10 October 1965.

BURKE, Peter. Uma história social do conhecimento II: Da enciclopédia à wikipédia. Rio de Janeiro: Editora Jorge Zahar, 2012.

BYNUM, William F. The Anatomical Method, Natural Theology, and the Functions of the Brain. Isis. Vol. 64. No 04. pp. 444-468. Dec., 1973.

CARROLL, Lewis. Some Popular Fallacies about Vivisection. Fortnightly Review. Vol. 17.102. May 1865-June 1934. Jun, 1875.

CASTELO, Carmen Velayos. Animales reales en el arte, o sobre los límites Èticos de la capacidad creadora. Revista Brasileira de Direito Animal/Brazilian Animal Rights Review. Vol. 02. Ano. 1. Jan/Jun. pp. 11-36. Salvador: Evolução, 2007.

CASTRO JÚNIOR, Marco Aurélio de. Direito e Pós-Humanidade: Quando os Robôs serão Sujeitos de Direito, Juruá, 2013.

CAVALIERI, Paola \& SINGER, Peter. (eds.). The Great Ape Project. New York: St. Martin's Griffin, 1993.

CHALFUN, Mery. Paradigmas filosóficos - ambientais e o direito dos animais. $R e$ vista Brasileira de Direito Animal. Vol. 06. pp. 209-246. Jan/Jun. Salvador: Evolução, 2010.

CHALMERS, Alan F. O que é ciência afinal? 2. ed. São Paulo: Ed. Brasiliense, 1993.

CHIASSONI, Pierluigi. L'inescusabile specismo del mangiatore di tartare divagazioni sui diritti degli animali. Revista Brasileira de Direito Animal. Vol. 07. Ano 05. jul./dez. pp. 13-41. Salvador: Evolução, 2010.

CLARKE, Stephen R. L. The Moral Status of Animals. Oxford: Oxford University Press, 1977.

DAMATTA, Roberto. Carnavais, Malandros e Heróis. Rio de Janeiro: Rocco, 1997.

DEBORD, Guy. A Sociedade do Espetáculo. Rio de Janeiro: Contraponto, 1997. 
DECKHA, Maneesha. Teaching Posthumanist Ethics in Law School: The Race, Culture, and Gender Dimensions of Student Resistance. Animal Law. Vol. 16.

DESCARTES, René. Discurso do Método e Regras para a direção do Espírito. Trad. Pietro Nassetti. São Paulo: Martin Claret, 2007.

DIAS, Edna Cardozo. A Defesa dos animais e as conquistas legislativas do movimento de proteção animal no Brasil. Revista Brasileira de Direito Animal. Vol. 02. n. 1. jan/jun. pp. 123-142. Salvador: Evolução, 2007.

2000.

. A tutela jurídica dos animais. Belo Horizonte: Mandamentos,

DIDIER JR., Fredie. Sobre a Teoria Geral do Processo, essa desconhecida. Salvador: JusPodivm, 2012.

DUCKLER, Geordie. The Economic Value of Companion Animals: A Legal and Anthropological Argument for Special Valuation. Animal Law. Vol. 08. pp. 199-221. 2002.

FARIA, José Eduardo. A Noção de Paradigma na Ciência do Direito: notas para uma crítica ao idealismo jurídico. In: FARIA, José Eduardo. (org). A Crise do Direito numa Sociedade em Mudança. Brasília: Editora UnB, 1988.

SANTOS, Boaventura de Sousa. Introdução a uma ciência pós-moderna. Rio de Janeiro, Graal, 1989.

FAVRE, David. O ganho de força dos Direitos dos animais. Revista Brasileira de Direito Animal. Vol. 01. No. 01, (jan/dez. 2006). Salvador: Instituto Abolicionista Animal, 2006.

. The Gathering Momentum. Journal of Animal Law Vol. 01. 2005.

Vol. 09. pp. 241-281. 1979.

. Wildlife Rights: The Ever Widening Circle. Environmental Law.

FAZENDA, Ivani Catarina Arantes. Interdisciplinaridade: História, Teoria e Pesquisa. Campinas, Editora Papirus, 1994.

FENSTERSEIFER, Tiago. Direitos Fundamentais e Proteção do Ambiente: a dimensão ecológica da dignidade humana no marco jurídico-constitucional do Estado Socioambiental de Direito. Porto Alegre: Livraria do Advogado, 2008.

FURLAN, Anderson \& FRACALOSSI, William. Direito ambiental. Rio de Janeiro: Forense, 2010.

GIMÉNEZ-CANDELA, María Teresa. New rules to ensure the protection of animals in Spain: Spanish Animal Welfare Act. 32/2007. Revista de Bioética y Derecho. No 14. pp. 25-28. Septiembre, 2008. 
- ¿Por qué estudiar Derecho Animal? In Teresa Giménez-Candela. (Org.). dA derecho ANIMAL la web center de los animales con derecho. Barcelona: Universitat Autonoma de Barcelona, October 2013

GLABERSON, William. Legal Pioneers Seek to Raise Lowly Status of Animals. The New York Times. Publicado em: 18 de Agosto de 1999. Disponível em: http:// query.nytimes.com/gst/fullpage.html?res=9500E2DE1638F93BA2575BC0A96F958260\&sec=\&spon=\&pagewanted $=2$. Acessado em: 01.08.2013.

GODLOVITCH, Stanley, GODLOVITCH, Rosalind and HARRIS, John (eds.), Animals, Man and Morals: An Enquiry Into the Maltreatment of Non-Humans, London: Taplinger Publish Co, 1971.

GORDILHO, Heron José de Santana. Abolicionismo Animal. Salvador: Evolução, 2009.

GRANGER, James. An Apology for the Brute Creation, Or Abuse of Animals Censured. In: Sermon on Proverbs XII. 10. Preached in the Parish Church of Shiplake, in Oxfordshire, October 18, 1772.

HARRISON, Peter. Descartes on Animals. Philosophical Quarterly. Vol. 42. pp. 239-48. 1992.

KEAN, Hilda. Animal rights: political and social change in Britain since 1800, Reaktion Books, 1998.

KELSEN, Hans, Teoria pura do direito. Trad. João Baptista Machado. 6. ed. São Paulo: Martins Fontes, 1998.

KEMP, Thierry Auffret Van Der. La Fondation LFDA: Qui? Pourquoi? Comment? Droit Animal, Éthique \& Sciences. N 75. Octobre, 2012.

KUHN, Thomas S. A Estrutura das Revoluções Cientificas. Trad. Beatriz Vianna Boeira e Nelson Boeira. 9. ed. São Paulo: Perspectiva, 2003.

LACABEX, María González. Sobre animales y desahucios. In Teresa GiménezCandela. (Org.). dA derecho ANIMAL la web center de los animales con derecho. Barcelona: Universitat Autonoma de Barcelona, August 2012.

LE BOT, Olivier. Direitos Fundamentais para os animais : uma ideia absurda ? Revista Brasileira de Direito Animal/Brazilian Animal Rights Review. Vol. 11. Ano 7. jul/dez. pp. 37-56. Salvador: Evolução, 2012.

LE BOT, Olivier. La protection de l'animal en droit constitutionnel. Etude de droit comparé. Lex Electronica. Vol. 12. N². pp. 01-54. Automne/Fall, 2007.

LEITE, Fátima Correia; NASCIMENTO, Esmeralda. Regime Jurídico dos Animais de Companhia. Coimbra, Almedina, 2004; De forma geral: SILVA, Vasco Pereira da. Verde Cor de Direito: Lições de Direito do Ambiente, Almedina, 2004. 
LEVAI, Laerte Fernando. Direito dos animais. O direito deles e o nosso direito sobre eles. Campos do Jordão: Editora Mantiqueira, 1998.

. \& DARÓ. Vânia Rall, Experimentação animal: histórico, implicações éticas e caracterização como crime ambiental. Revista de Direito Ambiental. São Paulo, Revista dos Tribunais, n. 36, out./dez., 2004.

LINZEY, Andrew. Animal Rights: A Christian Assessment of man's. London: SCM Press, 1976.

Vol. 80. pp. 60-81. Winter, 1998.

. CS Lewis's theology of animals. Anglican Theological Review.

LOURENÇO, Daniel. Direito dos Animais: fundamentação e novas perspectivas. Porto Alegre: Sergio Antonio Fabris, 2008.

MARGUÉNAUD, Jean-Pierre. La protection juridique du lien d'affection envers un animal, Dalloz 2004.

. Proposition pour surpasser la division des associations de protection des animaux. Revue Semestrielle de Droit Animalier - RSDA. Vol. 02. pp. 21-25. Juil/Déc, 2012.

MARTINS, Renata de Freitas. O respeitável público não quer mais animais em circos! Revista Brasileira de Direito Animal. Vol. 03. n.04. jan/dez. Salvador: Evolução, 2008.

MAYER, Jed. Ruskin, vivisection, and scientific knowledge. Nineteenth-Century Prose. Vol.35, Issue 1. pp. 200-266. Spring, 2008.

MEDEIROS, Fernanda Luiza Fontoura de. Direito dos animais. Porto Alegre: Livraria do Advogado, 2013.

MIGLIORE, Alfredo Domingues Barbosa. Personalidade Jurídica dos Grandes Primatas. Belo Horizonte: Del Rey, 2012.

MONTEIRO, Teresa Líbano, POLICARPO, Verónica \& SILVA, Francisco Vieira da (Coords.) Valores e Atitudes face à Protecção dos Animais em Portugal - Inquérito Nacional. In Centro de Investigação e Estudos de Sociologia (CIES) do ISCTE Instituto Superior de Ciências do Trabalho e da Empresa. Maio de 2007.

MORIN, Edgar. Ciência com Consciência. 8. ed. Rio de Janeiro: Bertrand Brasil, 2005.

MOUTINHO, Miguel. O Direito dos Animais e os Direitos dos Animais. In Os animais e a lei. Publicado em 11 de Abril de 2009. Disponível em: http://osanimaisealei. blogspot.com.br/2009/04/o-Direito-dos-animais-e-os-Direitos-dos.html. Acessado em: 03.08.2013. 
MULÀ, Anna. La iniciativa legislativa popular de abolición de las corridas de toros en Cataluña. Revista de Bioética y Derecho. N ${ }^{\circ}$ 20. pp. 27-32. Septiembre, 2010.

NACONECY, Carlos. Review Ethics and Animals: An Introduction Gruen Lori Cambridge University Press Cambridge, England. Journal of Animal Ethics. Vol. 02. pp. 222-224, 2012.

NEWMAN, John Henry. Sermon Notes, 1849-1878. Longmans, Green \& Co, 1913. NICHOLSON, Edward Williams Byron. The rights of an animal: a new essay in ethics. C. Kegan Paul \& Co, 1879.

NOGUEIRA, Vânia Márcia Damasceno. Direitos Fundamentais dos Animais: a construção jurídica de uma titularidade para além dos seres humanos. Belo Horizonte: Arraes Editores, 2012.

NOUËT, Jean-Claude. Régime juridique de l'animal. Droit Animal, Éthique \& Sciences. N 74 . Juillet, 2012.

OBERST, Anaiva. Direito Animal. Rio de Janeiro: Lumen Iuris, 2012.

OLIVEIRA, Fábio Corrêa Souza de. Direitos da Natureza e Direito dos Animais: Um Enquadramento. Revista do Instituto do Direito Brasileiro da Faculdade de Direito da Universidade de Lisboa-RIDB. Vol. 10. pp. 11325-11370. 2013.

OLIVEIRA, Thiago Pires. Redefinindo o Status jurídico dos animais. Revista Brasileira de Direito Animal. Vol. 03. jul/dez. 2007.

ORTIZ, Fran. Animal Law in the Classroom. Texas Bar Journal. Vol. 74. N 10. p. 902-904. November 2011.

OSTER, Malcolm R. The 'Beame of Diuinity': Animal Suffering in the Early Thought of Robert Boyle. The British Journal for the History of Science. Vol. 22. No. 2. pp. 151-179. Jul, 1989.

PAIXÃO, Rita Leal \& SCHRAMM, Fermin Roland. Experimentação Animal. Razões e emoções para uma ética. EdUFF, Niterói, RJ, 2008.

PATERSON, David \& RYDER, Richard D. Animals' Rights: A Symposium. Open Gate Press, 1979.

PERRY. Nancy V. Ten Years of Animal Law at Lewis \& Clark Law School. Animal Law. Vol. 09. p. ix-xv. 2003.

POPPER, Karl. Lógica das ciências sociais. 2. ed. Rio de Janeiro: Tempo Universitário, 2004.

REGAN, Tom. A causa dos direitos dos animais. Revista Brasileira de Direito Animal. Vol. 08. № 12. Jan/abr. 2013. BOURDIEU, Pierre. O Poder Simbólico. 6. ed. Rio de Janeiro: Bertrand Brasil, 2003. 
REGAN, Tom. The Case for Animal Rights. In: Peter Singer (ed), In Defense of Animals. New York: Basil Blackwell, 1985.

REGAN, Tom. The More Things Change. A review of Richard Ryder's. Animal Revolution: Changing Attitudes. Towards Speciesism. Between the Species. pp. 110115. North Carolina State University, Spring 1991.

. The More Things Change. A review of Richard Ryder's. Animal Revolution: Changing Attitudes. Towards Speciesism. Between the Species. pp. 110115. North Carolina State University, Spring 1991.

RODRIGUES, Danielle Tetü. O Direito \& os Animais: uma abordagem ética, filosófica e normativa. 2. ed. Curitiba: Juruá, 2008.

RYDER, Richard D. Os animais e os Direitos humanos. Revista Brasileira de Direito Animal. Vol. 04. pp. 67-70, 2008.

Issue 2, 2010.

. Speciesism Again: The Original Leaflet. Critical Society. Spring,

. The Oxford Group. In BEKOFF, Marc, and CARRON Meaney.

Encyclopedia of Animal Rights and Animal Welfare. Westport, CT: Greenwood Publishing Group, Inc., 1998.

David-Poynter, 1975.

. Victims of Science: The Use of Animals in Research. London:

. Animal Revolution: Changing Attitudes Towards Speciesism. Basil Blackwell, 1989.

SALT, Henry S. Animals' rights. In Animal rights and human obligations. New Jersey: Prencitce-hall, 1976.

SANKOFF. Peter, Charting the Growth of Animal Law in Education. Journal of Animal Law. Vol. 04. pp. 105-148. 2008.

SANKOFF. Peter, Charting the Growth of Animal Law in Education. Journal of Animal Law. Vol. 04.

SANTANA, Luciano Rocha \& SANTOS, Clarissa Pereira Gunça dos. O crime de maus-tratos aos animais: uma abordagem sobre a interpretação e a prova de materialidade e autoria (artigo 32). In MARCHESAN, Ana Maria Moreira \& STEIGLEDER, Annelise Monteiro. (org.). Crimes Ambientais Comentários à Lei 9.605/98. Porto Alegre: Livraria do Advogado, 2013.

SENATORI, Megan A. \& FRASCH, Pamela D. The Future of Animal Law: Moving Beyond Preaching to the Choir. Journal of Legal Education. Vol. 60. n.02. pp. 209236. November, 2010. 
SILVA, Tagore Trajano de Almeida. Capacidade de ser parte dos Animais Não-Humanos: Repensando os Institutos da Substituição e Representação Processual. In Teresa Giménez Candela. (Org.). dA derecho ANIMAL la web center de los animales con derecho. Barcelona: Universitat Autónoma de Barcelona, Septiembre, 2010.

. Brazilian Animal Law Overview: Balancing Human and Non-Human Interests. Journal of Animal Law. Vol. 06. pp. 81-104. 2010.

. Animais em juizo: direito, personalidade jurídica e capacidade processual. Salvador: Evolução, 2012.

. Direito Animal e os paradigmas de Thomas Kuhn: Reforma ou Revolução Científica na Teoria do Direito? In: Rodolfo Pamplona Filho; Nelson Cerqueira; Gilson Alves de Santana Júnior. (Org.). Metodologia da Pesquisa em Direito. Salvador: UFBA, 2010, v. 01.

. Introdução aos direitos dos animais. Revista de Direito Ambiental. Vol. 62. pp. 141-168, 2011.

. Teoria da Constituição: Direito Animal e Pós-Humanismo. Revista do Instituto do Direito Brasileiro da Faculdade de Direito da Universidade de Lisboa-RIDB. Vol. 10. pp. 11683-11732, 2013.

SIMPSON, Matthew. Coetzee in Oxford. Oxford Magazine. N ${ }^{\circ} .289$. Trinity Term 2009.

SINGER, Peter. Animal liberation. The New York Review of Books. Vol. 20. № 05. Publicado em 05 de Abril de 1973.

. Animal Liberation: a New Ethics for our Treatment of Animals.

New York: New York Review/Random House, 1975.

. Famine, Affluence, and Morality. Philosophy and Public Affairs.

Vol. 01. n. 01. pp. 229-243. Spring, 1972.

TAFALLA, Marta. La apreciación estética de los animales. Consideraciones estéticas y éticas. Revista de Bioética y Derecho. N² 28. , pp. 72-90. Mayo, 2013.

. Sobre perros y justicia: a propósito de la prohibición del sacrificio de perros abandonados en Catalunya. Revista de Bioética y Derecho. № 06. p. 01-05. Marzo, 2006.

THOMAS, Keith. O homem e o mundo natural: mudanças de atitude em relação às plantas e aos animais $(1500$ - 1800). Trad. João Roberto Martins Filho. São Paulo: Companhia das Letras, 2010.

TISCHLER, Joyce. A Brief History of Animal Law, Part I (1972-1987). Stanford Journal of Animal Law and Policy. Vol. 01. pp. 01-49. 2008. 
TISCHLER, Joyce. A Brief History of Animal Law, Part II (1985 -2011). Stanford Journal of Animal Law and Policy. Vol. 5. pp. 27-77. 2012. . Building our Future. Animal Law. Vol. 15. pp. 01-07. 2008.

TUGLIO, Vânia. Rodeios e crueldade contra animais. Revista de Direito Ambiental. Vol. 10. 2005.

WAISMAN, Sonia S.; FRASCH, Pamela D. \& WAGMAN, Bruce. A. Animal Law: Cases and Materials. 3. ed. Durham, NC: Carolina Academic Press 2006.

WALDAU, Paul. Law \& Other Animals. In Teaching the Animal: Human-animal studies across the disciplines New York: Margo DeMello ed, 2010.

WARREN, Marry A. Moral Status: Obligations to Persons and Other Living Things. Oxford: Oxford University Press, 1997.

WISE, Steven M. Animal Thing to Animal Person - Thoughts on Time, Place, and Theories. Animal Law. Vol. 05. pp. 61-68. 1999.

. The Entitlement of Chimpanzees to the Common Law Writs of Habeas Corpus and de Homine Replegiando. Golden Gate Law Review. Vol. 37.2. Winter, 2007.

Animals II: 2003. . The Evolution of Animal Law since 1950. In The State of the 